\title{
Informal carers' experience of assistive technology use in dementia care at home: a systematic review
}

Vimal Sriram ${ }^{*}$ (D), Crispin Jenkinson and Michele Peters

\begin{abstract}
Background: Dementia is a health and care priority globally. Caring for persons with dementia is a challenge and can lead to negative psychological, physiological and financial consequences for informal carers. Advances in technology have the potential to assist persons with dementia and their carers, through assistive technology devices such as electronic medication dispensers, robotic devices trackers and motion detectors. However, little is known about carers' experience and the impact of these technologies on them. This review aims to investigate the outcomes and experience of carers of persons with dementia, who live at home and use assistive technology.
\end{abstract}

Methods: A systematic search in seven databases and manual searches were carried out using pre-defined inclusion and exclusion criteria to identify studies on carers of persons with dementia involving the use of assistive technology. The search identified 56 publications with quantitative, qualitative and mixed-method designs.

Results: The studies reported positive and negative findings and focused on a wide variety of assistive technology devices. There were large differences in the uses of assistive technology, outcome measures used and the quality of studies. Knowledge and acceptance, competence to use and ethical issues when using assistive technology were themes that emerged from the studies. Carers generally appreciated using assistive technology and their experience of use varied.

Conclusions: The intention of this systematic review is to list and classify the various types of assistive technology used by carers of persons with dementia and explores the positive and negative aspects, knowledge, acceptance and ethical issues in the use of assistive technology by carers of persons with dementia. We recommend the use of a standard and person-centred system of classifying and naming assistive technology devices and systems and for future research efforts in assistive technology to incorporate a family/carer centred model.

Systematic review registration: PROSPERO - CRD42017082268.

Keywords: Dementia, Assistive technology, Carers, Well-being, Systematic review, Quality of life

\footnotetext{
* Correspondence: vimal.sriram@dph.ox.ac.uk

Health Services Research Unit, Nuffield Department of Population Health,

University of Oxford, Richard Doll Building, Old Road Campus, Oxford OX3

7LF, UK
}

(c) The Author(s). 2019 Open Access This article is distributed under the terms of the Creative Commons Attribution 4.0 International License (http://creativecommons.org/licenses/by/4.0/), which permits unrestricted use, distribution, and reproduction in any medium, provided you give appropriate credit to the original author(s) and the source, provide a link to the Creative Commons license, and indicate if changes were made. The Creative Commons Public Domain Dedication waiver (http://creativecommons.org/publicdomain/zero/1.0/) applies to the data made available in this article, unless otherwise stated. 


\section{Background}

Dementia is a complex acquired brain condition characterised by a decline from a previous level of cognitive functioning with impairment in cognitive domains [1]. Worldwide there are an estimated 50 million people who have dementia and nearly 10 million new cases every year [2]. Informal carers (families, friends and neighbours) provide the majority of care for persons with dementia [3]. Dementia can be overwhelming for carers of persons with dementia and can cause stress from physical, emotional and economic pressures [4-6]. Stretched health and care resources necessitate alternative and innovative ways to providing care for persons living with dementia [7]. Assistive technology (AT) has been suggested as a means to support someone who has dementia and their carers to stay independent and remain in the community [8-11]. AT can be defined as: "any item, piece of equipment, product or system that is used to increase, maintain or improve the functional capabilities and independence of people with cognitive, physical or communication difficulties" [12]. The use of AT by persons living with dementia may by extension also benefit the carer, as it could offer the potential to increase the support to carers and alleviate some of the burden of caregiving [13-16]. AT may assist carers to address the increased level of responsibility whilst caring for a person with dementia $[17,18]$. Additionally, carers of someone who has dementia are in the unique position of using their preconceived ideas regarding AT to suggest and decide on the access to and use of AT [19], yet very little is known about carers' experiences of AT use.

\section{Why it is important to do this review}

Currently, AT and Artificial Intelligence driven healthcare solutions are being viewed as a panacea for reducing carer burden $[20,21]$ and multiple studies are investigating how AT can support people with dementia [22-24]. Carers could be using the AT together with the person with dementia (such as safety alarms) and/or carers could be looking after someone who has dementia, who uses AT independently of the carer. Yet, little is known about the experiences of carers using AT and what impact AT has on carer health and wellbeing [25]. This review, aims to fill the gap in literature that so far has predominantly looked at AT from the perspective of people living with dementia and its use within institutional settings $[7,26,27]$ as well as identifying carer wellbeing when using AT. This information could benefit carers and persons with dementia considering AT solutions for use at home, help healthcare professionals who prescribe and set up AT solutions, as well as developers/inventors of AT.

\section{Review aim and questions}

This review aims to:

1) Identify the types and uses of AT in dementia;

2) Describe the effectiveness of AT for outcomes (including burden, well-being and quality of life) of carers of people with dementia living at home;

3) Describe carers' experiences of AT use in dementia;

4) Determine the aspects of AT that are valued and work well for carers by integrating (2) and (3) as above.

\section{Methods}

The review protocol was registered with the international prospective register of systematic reviews PROSPERO (CRD42017082268). The Preferred Reporting Items for Systematic Reviews and Meta-Analyses (PRISMA) checklist is included as Additional file 4.

\section{Types of studies}

Quantitative, qualitative and mixed method study designs were included. Letters to the editor, abstract and conference proceedings, book reviews, study protocols and theses/dissertations were excluded. We did not include other reviews but checked references within identified existing reviews on dementia, informal carers and AT to ensure that all relevant studies had been located. Due to funding constraints, only studies in English language or those translated to English language were included.

\section{Evaluation of effectiveness}

We included all randomised and controlled trials that compared AT for carers of someone who has dementia to those not provided with the AT, and who received usual care. We also included observational and cohort studies.

\section{Evaluation of experience}

We included studies that used qualitative methods of data collection and analysis, either as a stand-alone qualitative study or as part of a mixed-method study.

\section{Types of participants}

Studies that included carers who provide unpaid care for a person living with dementia at home were included. Providing care is defined for the purposes of this study as 'supporting a person with dementia physically, emotionally, financially or socially' and care could be provided by a relative, a friend or a neighbour. There were no restrictions regarding gender, living arrangements or ethnic background. Studies reporting on carers who provide support to a person living with dementia receiving care in hospital and/or long-term institutions and carers 
younger than 18 years and formal/paid carers were excluded.

\section{Types of assistive technology}

For this review, studies that evaluate AT use in dementia involving carers were included. AT was defined as 'any advanced electronic equipment, which can be used to enhance support and care, act as a prompt for intervention by carers, monitor welfare and assist in communication and leisure activities for a person with dementia'. This AT can be standalone (e.g. Tablet computers) or be part of an integrated system (e.g. GPS and sensor trackers) and can be stationary or mobile. As the focus of most research studies invariably is on the person living with dementia, any study that reported on effects or experiences of AT use on carers were included. Studies that reported only on AT use for people with dementia without including carers were excluded, as were studies that focus only on electronic therapeutic interventions that are not AT (e.g. computer-based education or support for carers).

\section{Types of study outcome measures}

The search was not limited to specific types of outcome measures and included carer self-reported outcome measures of burden; quality of life; and well-being; and self-reported or researcher observed experiences of usefulness; benefits and disadvantages of AT and impact on carer /person living with dementia relationship.

\section{Search strategy}

The search strategy was developed in collaboration with a Bodleian medical library librarian at the University of Oxford.

Searches were carried out on:

\section{Databases}

Including MEDLINE (Ovid) from 1946 to June 2018; EMBASE from 1974 to June 2018; PsycINFO from 1806 to June 2018; AMED 1985 to June 2018; CINAHL from 1981 to June 2018; Database of Abstracts of Reviews of Effects (DARE), OT seeker and The Cochrane Library of Systematic Reviews. The search included studies within ALOIS (from inception to June 2018).

\section{Unpublished literature}

The International Standard Randomised Controlled Trials Number (ISRCTN) registry [28] and the National Institutes of Health Clinical Trials Database [29] were searched for information on unpublished ongoing trials. Searches within these databases were used to identify additional studies and authors to contact for full text reports.

\section{Manual searches}

We also conducted manual searches of reference lists to identify relevant research studies.

Details of the full search, with search strategies and the number of records identified in each database are included in Additional file 1.

\section{Screening}

Electronic search results were downloaded into Covidence software [30] (an online digital platform that streamlines the production of systematic reviews and allows screening and data extraction between collaborating reviewers) as .ris files. Duplicates were removed using the software. Authors VS and MP independently screened all titles and abstracts for eligibility against the inclusion/exclusion criteria. For studies that had insufficient information from the title and abstract, full text articles were retrieved to determine inclusion. Studies marked for possible inclusion underwent a full-text review. At full-text review, when both VS and MP agreed that a study did not meet the full eligibility criteria, the study was excluded. CJ was consulted when VS and MP did not agree on a study. Discrepancies were resolved by mutual discussion.

\section{Data extraction}

A bespoke data extraction form (Additional file 2) developed by all the authors was used and initially piloted on a sample of studies to refine the form. Data from the studies were logged using Microsoft Excel 2016. There were no deviations from the published protocol.

\section{Effectiveness}

Data extraction items from quantitative studies were based on the recommended items from the Cochrane handbook for systematic reviews of interventions [31]. Information on citation including authors, date of publication, study design, duration, number of participants, participant gender, age, ethnicity, country where the study took place, relationship status to the person living with dementia, types and use of the AT, outcome measures used, time points of data collection, missing participants and key conclusions from the study authors were extracted.

\section{Experience}

In addition to collecting information from qualitative studies on citation, author details, study design, duration, and participant information, country and time points when information was collected, VS extracted data based on study authors' commentaries and conclusions [32, 33]. MP and CJ checked extracted data for accuracy and completeness. Disagreements and clarifications were resolved by discussion among the authors. 


\section{Results}

The first search was carried out in December 2017 and repeated in June 2018. A check for duplicate records was carried out electronically. To confirm results gained from Covidence [30] an additional screening using reference management software Mendeley [34] was undertaken. From the 11,553 records retrieved from database search 3635 were removed as duplicates. The titles and abstracts of the 7918 retrieved records were independently screened by VS and MP. A total of 7746 records were excluded (including further duplicate records) and full-text articles for the remaining 172 records were independently assessed for inclusion based on full texts by VS and MP. Fifty-six papers met the inclusion criteria and were included in this review for data extraction. Reasons for exclusion of the full-text papers were documented and are listed separately (Fig. 1).

\section{Included studies}

Of the 56 included publications, 30 were qualitative, 17 quantitative and 9 mixed-methods reporting on a total of 50 studies from 19 countries. There were 2 Randomised Controlled Trials (RCTs) and 1 Controlled Clinical Trial. The publications were from 2000 to 2018, reporting on findings from 2016 carers $(660$ men and 1165 women, where gender was reported) and 84 types of AT. Carers' age ranged from 19 to 91 years, with 13 publications not reporting an age range for participants. Several methods were used for data collection including interviews (32), surveys (14), observations (8), focus groups (7), questionnaires (6), diary/log entries (4) and video recording and email and blog reviews (1 each), with 19 studies using more than one method for data collection. Seven studies [35-42] reported on ethnic backgrounds of participants which were predominantly from white backgrounds alongside Hispanic, African American, Asian and 'other' backgrounds. Most studies reported the severity and type of dementia, without specifying a classification system; for ease of use, we have followed the 3-stage classification system of clinical dementia rating assessment [43]. Where reported in the studies, most studies involved people with dementia who had mild or moderate dementia. The carer relationship to the person with dementia ranged from spouses, siblings, children, daughter/son-in-law, nieces and nephews, grandchildren, neighbours and friends. Some studies included paid carers and participants who lived in long-term care facilities alongside carers of someone who has dementia living at home. The results described in this review relate only to family carers and persons with dementia who lived at home from those studies.
Quality of included studies: appraisal of included studies As this review involved quantitative, qualitative and mixed-method studies, the Mixed Methods Appraisal Tool $[18,44,45]$ for assessing quality of included studies was used. MMAT scores are provided (Additional file 3) for the included publications. The score is a subjective appraisal of a study's methodological quality. For qualitative and quantitative studies, the percentage of criteria met is stated. For mixed-methods studies, the overall score cannot exceed the lowest score of a component, so if one part received $100 \%$ but the other $50 \%$, the overall score would be $50 \%$. This means it would be possible for a study to have a strong quantitative section and a weaker qualitative section, or vice-versa, but the overall score would be low, suggesting the study might be less valuable [18]. The included studies were critically evaluated by VS and discussed with MP and CJ with discrepancies resolved through discussion. A majority of the included publications scored over $50 \%$ on the MMAT score with six of the qualitative studies [46-51] scoring highly for due consideration of results in context and for researchers' own influence on data collection and interpretation of results. The RCTs $[35,36]$ and the controlled clinical trial [37] scored poorly on allocation concealment and blinding and the RCT pilot trial [36] also had a high attrition rate. While not ignoring the strengths and weaknesses of the studies, we have included all studies, to answer the questions for this review and add to the richness of our findings. Results are presented in line with the questions that this systematic review set out to explore. Characteristics of the included papers are presented in Table 1 and additional details are available in Additional file 3.

\section{Data synthesis}

As the included studies were a mixture of quantitative, qualitative and mixed-methods studies, we completed a narrative synthesis of the evidence [32, 33, 93-95]. The narrative synthesis aims to present a descriptive summary of findings across the included studies and themes relevant to the aims of this review, such a synthesis can produce new insights and understanding from different aspects and provides a more informed view of carer experience with AT. Lins et al. describe that when "descriptive qualitative studies that are characterised by 'thin descriptions' are available, an aggregative method is more appropriate; if the identified evidence includes a high proportion of in-depth qualitative studies characterised by 'thick descriptions', an interpretative method can be applied" [96]. Since all of the qualitative studies in this systematic review had 'thin descriptions' available we used an aggregative method for qualitative synthesis.

We followed the method of Timulak [97] for qualitative data synthesis. We transferred data from the 


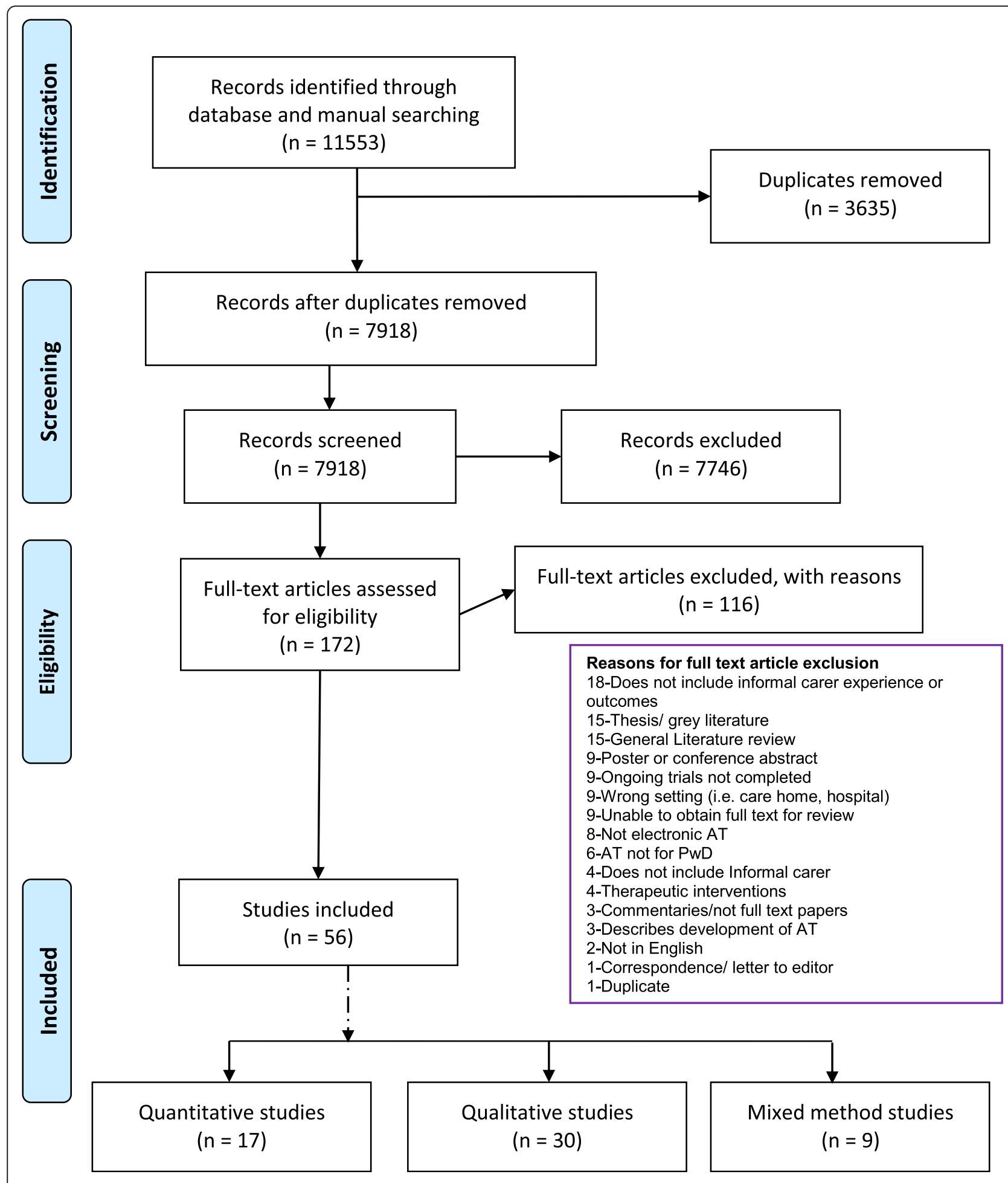

Fig. 1 PRISMA flow diagram of study selection

extracts of the included studies into data analysis software NVivo Version 12 [98]. The first step of the analysis was to read and get familiarised with the included studies. This was followed by creating a conceptual framework of categories on carers' experiences as an emerging process using a few studies. Subsequent studies were coded into pre-existing concepts, and new categories were created when deemed necessary. As a third step, from these categories, themes of meaningful units are described and presented as findings. VS extracted 


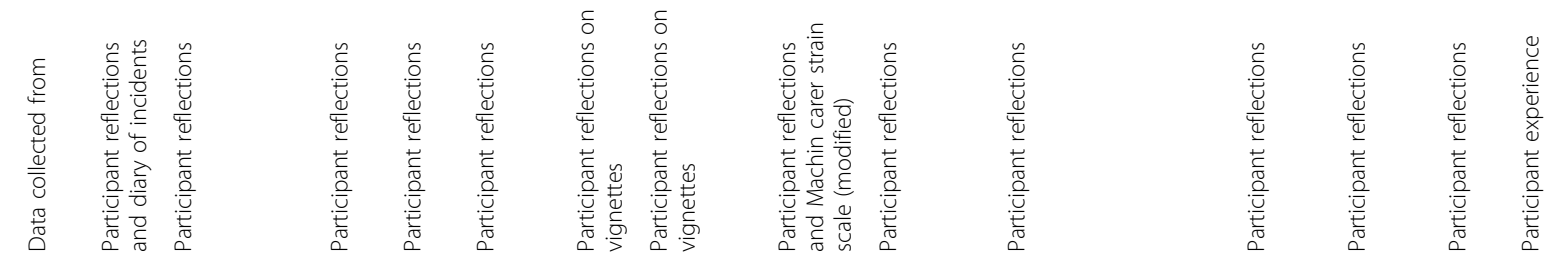

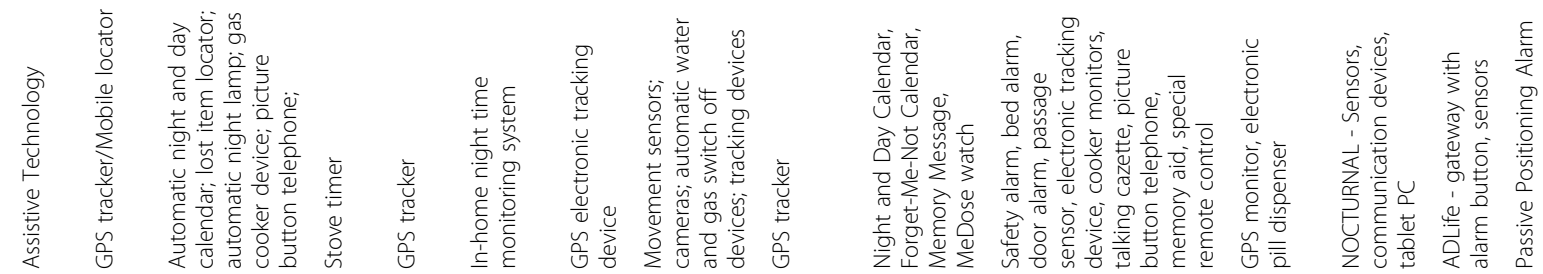

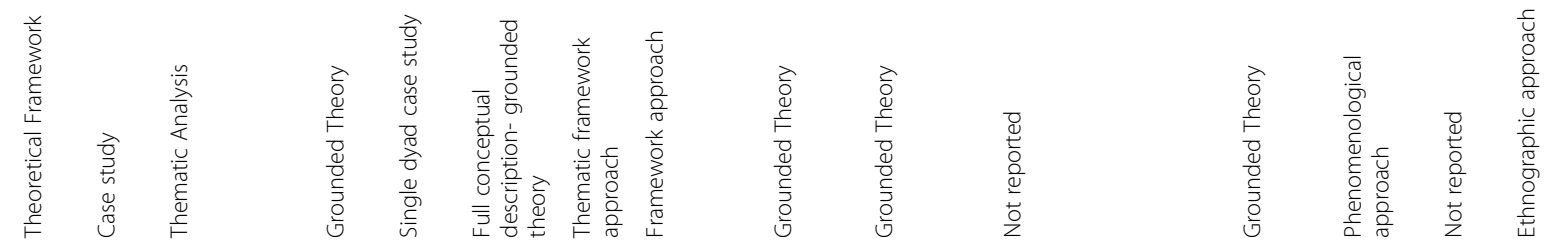

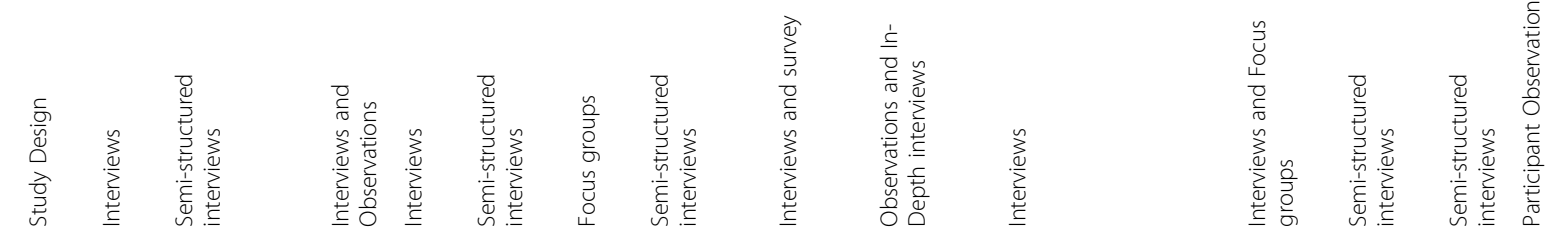

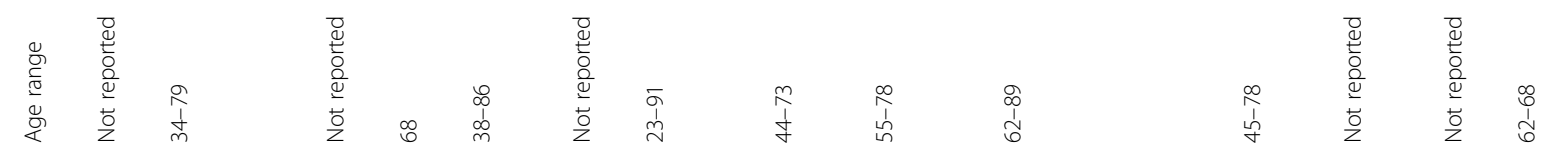

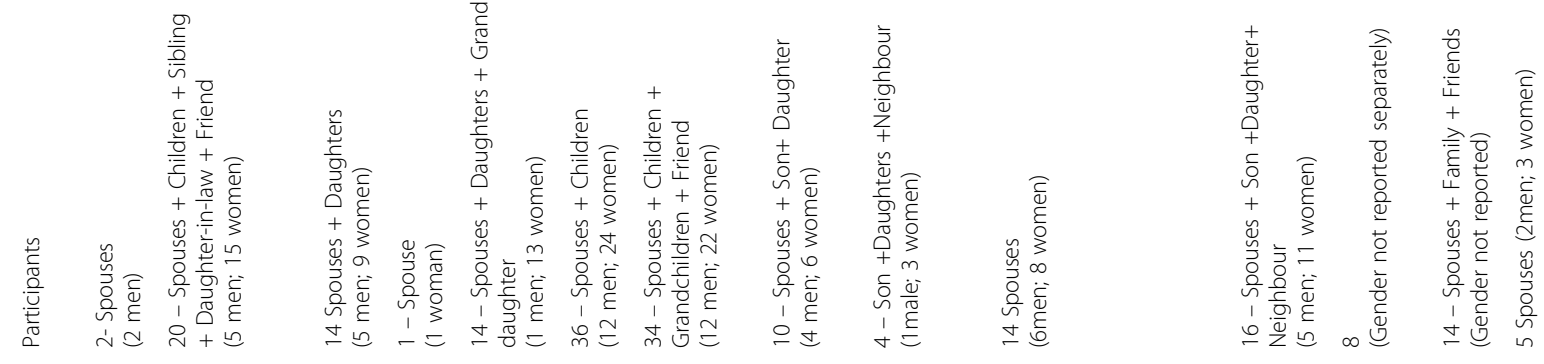

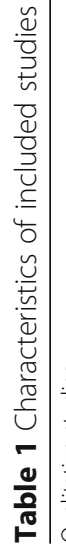

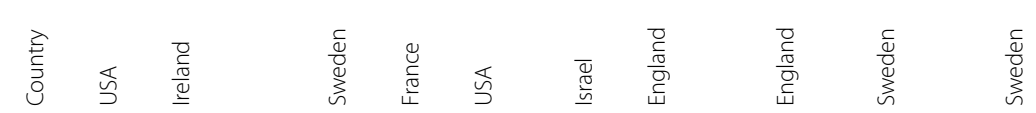

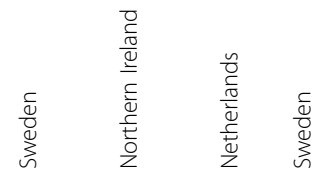

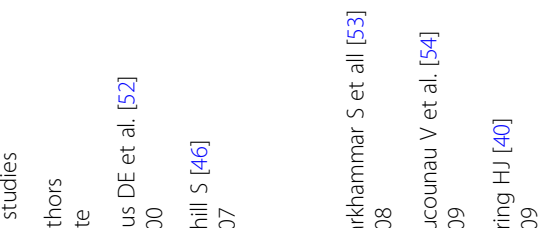

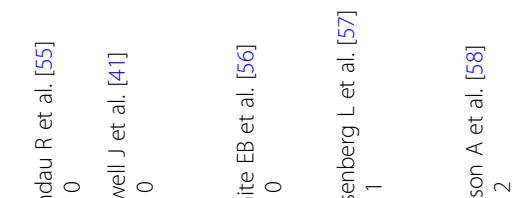

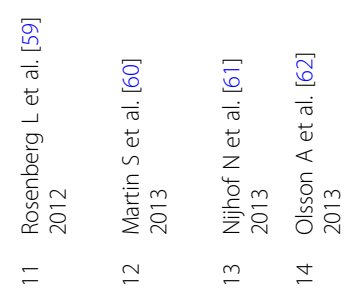




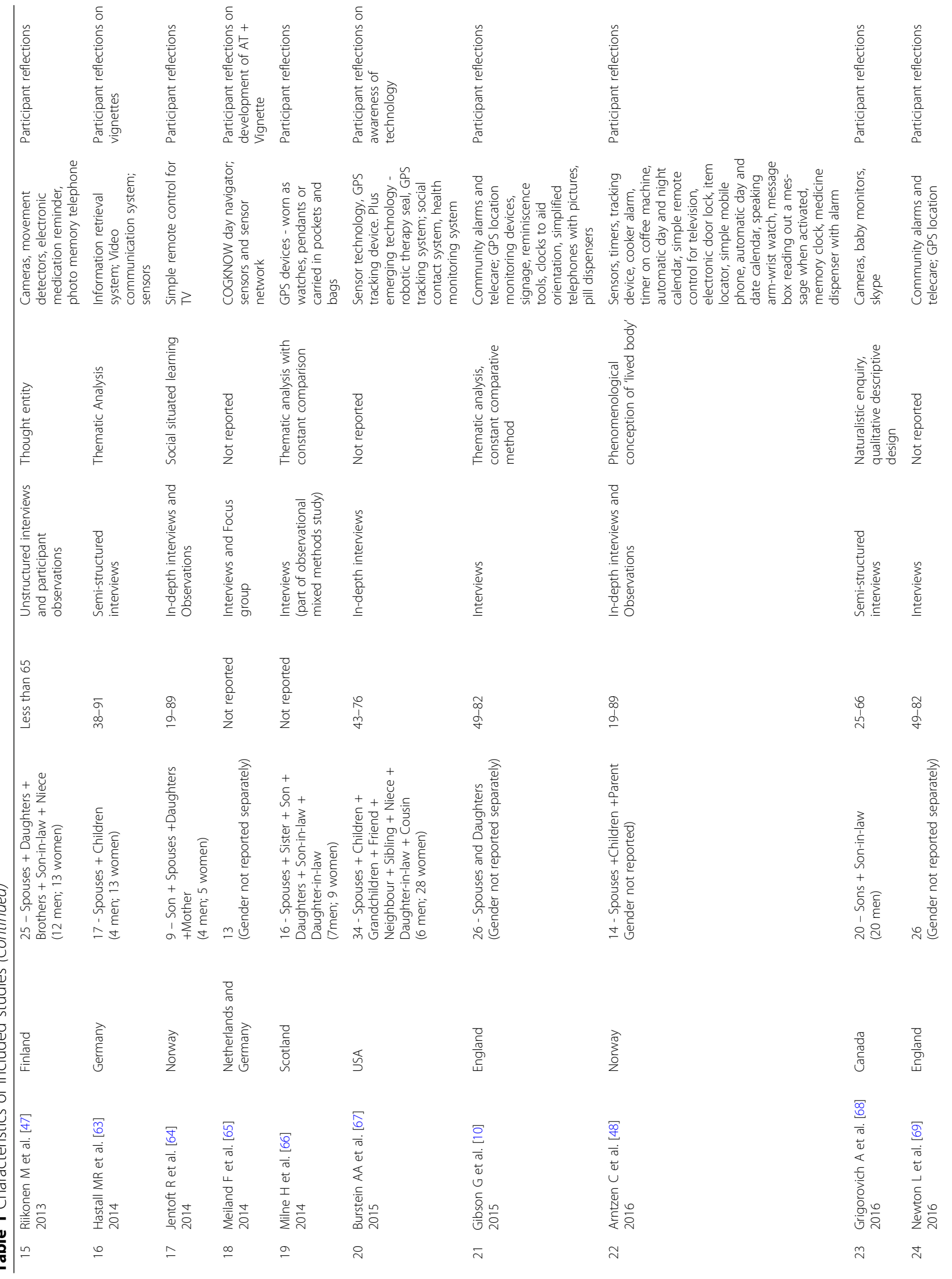



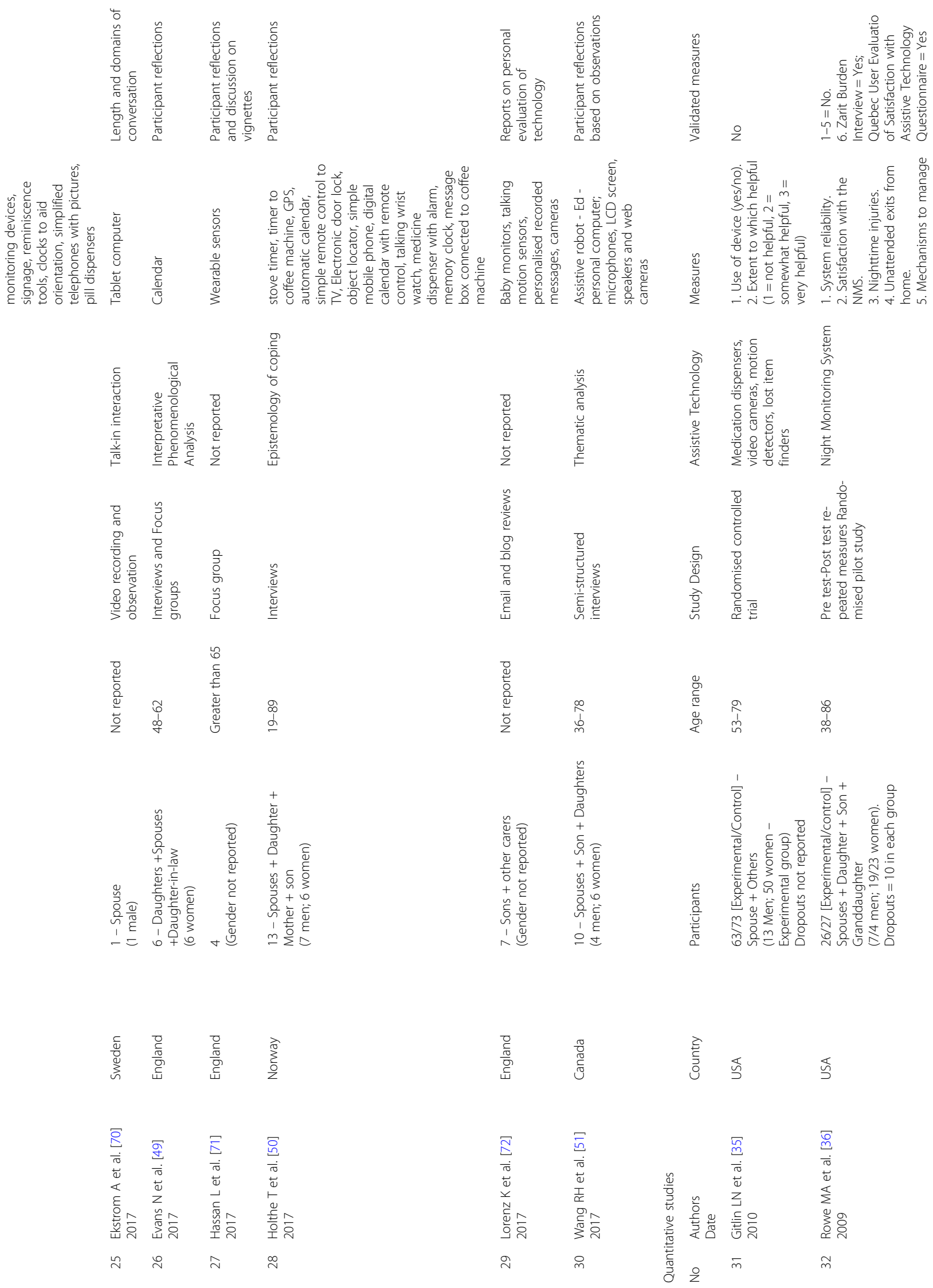


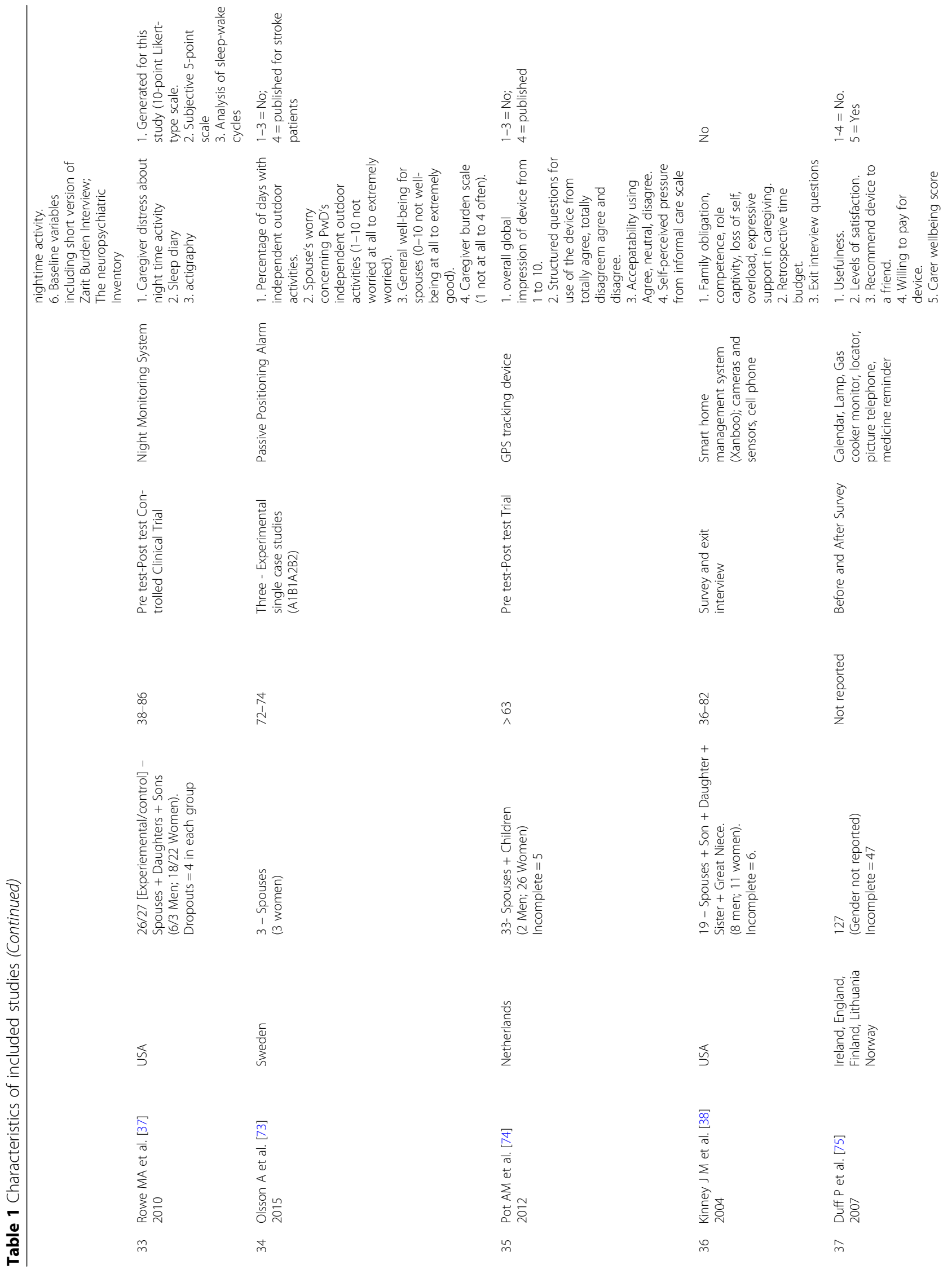




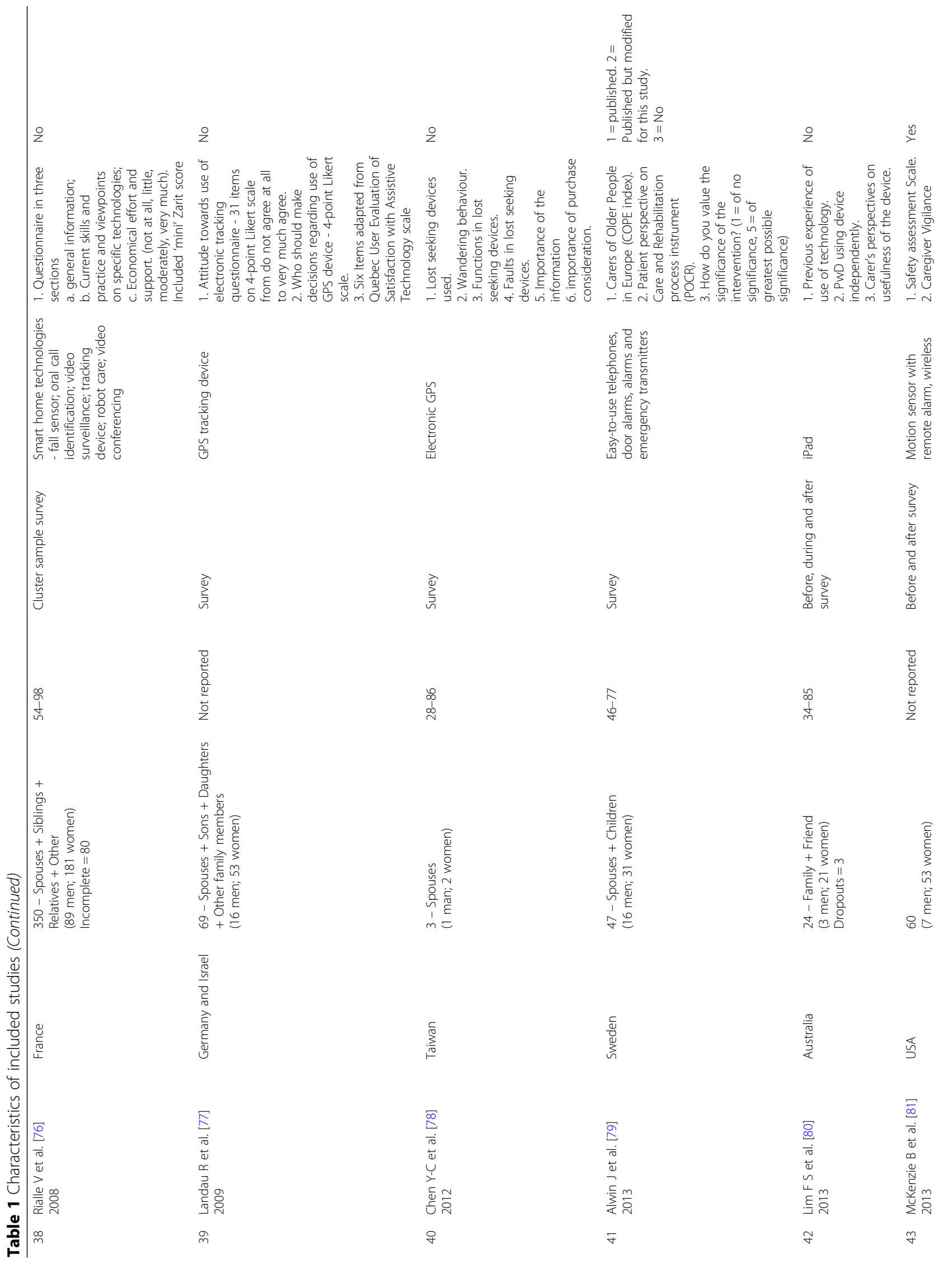




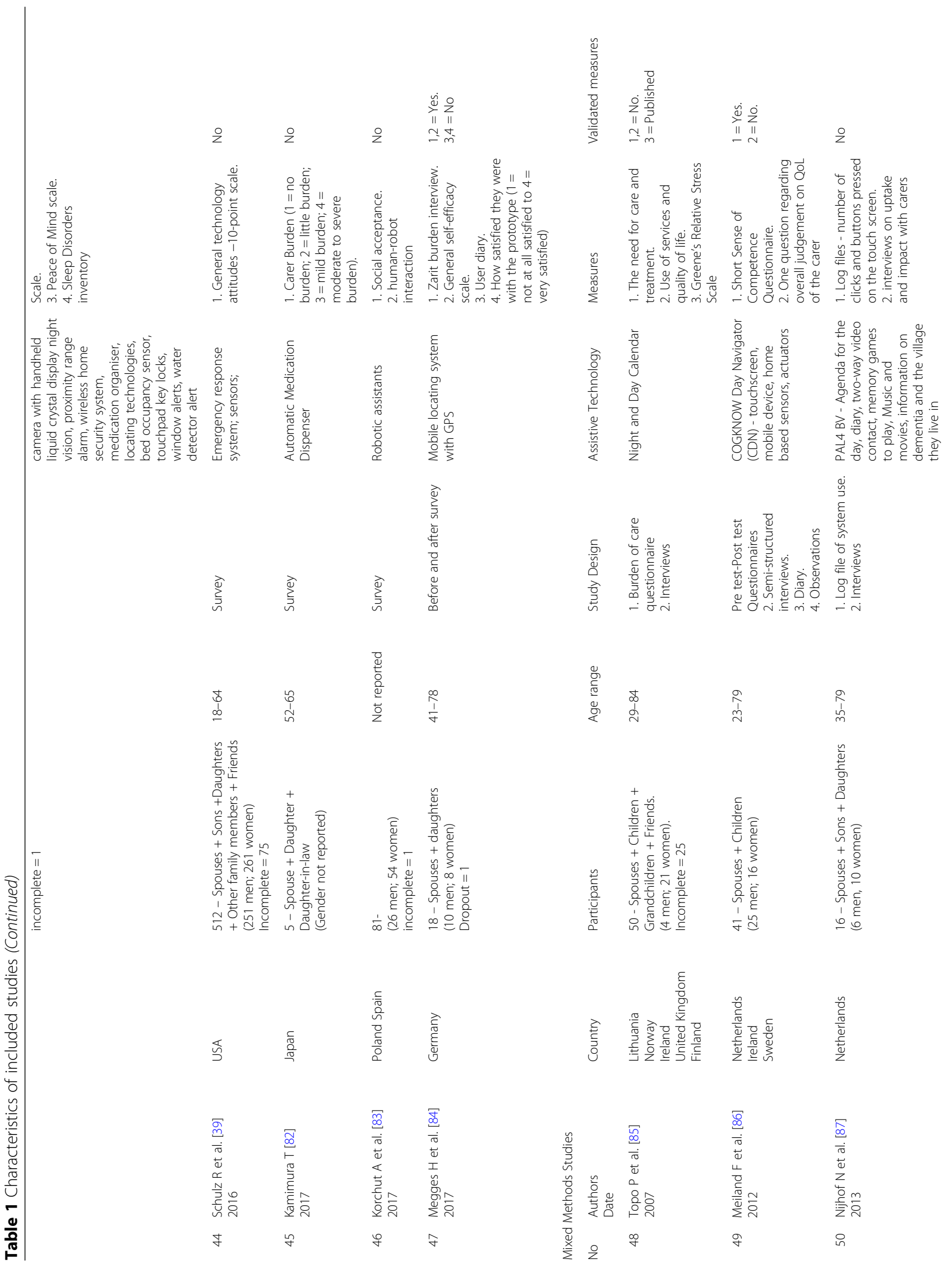




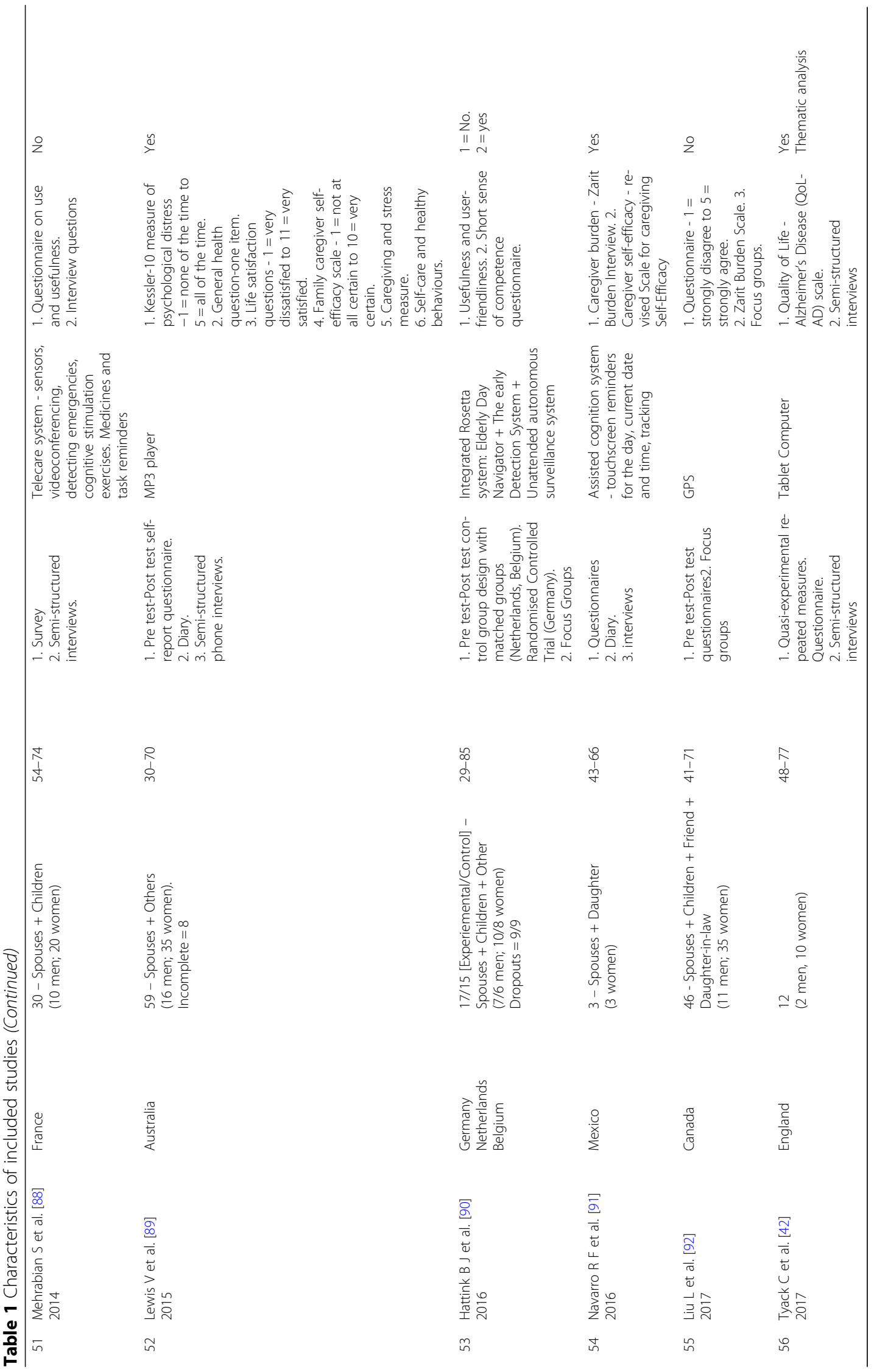


and summarised the data for the results. MP and CJ reviewed and highlighted outstanding issues and final themes were subsequently arrived at through discussions. As this is an aggregative synthesis, we maintained reflexivity throughout the review process through discussions and reflections on extracted data and coding.

\section{Question 1: identify the types and uses of AT in dementia}

To date, there appears to be no agreed way of classifying AT available for use by people with dementia, and we have classified them by their use as part of this review. A list of AT described in the included studies (Table 2) was created with uses of the AT classified based on work developed by AT dementia [99] and Lorentz et al. [72]. From the included studies, AT is a mixture of active (requires action or interaction from the part of the person living with dementia or carer) and passive devices. Some devices had multiple uses e.g. the electronic medication reminders acted both to orient the person with dementia to time when they needed to take their medication as well as acting as a safety device to ensure they took important medication on time. 64 of the AT products described in the studies were commercially available with 10 studies describing AT that were research prototypes.

The most commonly used AT was for safety and security $(n=38)$ including tracking devices and home safety devices. Followed by devices used for supporting memory and orientation for the person living with dementia $(n=23)$ and for social interaction and leisure activities $(n=16)$. In this review, very few studies $(n=3)$ considered AT which supported basic Activities of Daily Living activities such as feeding, washing, grooming or dressing. The AT used (including some research prototypes) are adapted from aids/devices that many people, with and without cognitive impairment, already use. None of the AT were for advanced instrumental Activities of Daily Living, such as managing finances, shopping or preparing meals and none of the AT addressed behavioural issues such as aggression or disinhibition, which is quite common in someone who has dementia.

\section{Question 2: describe the effectiveness of AT for carers}

The included studies reported on a wide range of careroriented measures (Zarit Burden interview, satisfaction with AT, carer well-being score), many of which were created for a specific study. A list of outcome measures used is presented in Additional file 3. Not all included studies reported on the effectiveness of AT for carers and due to the wide range of outcome measures and uses of AT, a descriptive summary of reported changes is provided (Table 3). From the 16 quantitative studies (17 publications), AT were reported as 'somewhat' or 'very useful' and AT is viewed as an adjunct to caregiving. There were no significant changes in carer reported well-being or burden. Surprisingly none of the studies considered or reported adverse events from AT use. Generally, carers reported they would recommend use of AT to others in similar situations, especially AT that supported safety and security for people with dementia. Where this was specifically asked, carers reported wanting to continue to use the AT, after the trial period. AT devices for safety, including tracking devices were the most used and appreciated by carers.

\section{Question 3: describe carers' experiences of AT use in dementia}

Thematic synthesis from the qualitative data generated 4 themes and 15 sub-themes. Quotations from studies to support themes and sub-themes are listed in Table 4.

\section{Positive aspects}

All the studies reported that the experience of cares using AT was generally positive.

Relationships The use of AT for leisure and social interaction, memory support; orientation; safety and security seemed to help strengthen relationships between the person living with dementia and their carers. The AT was perceived as helping the carer function better in their caregiving role and became a 'member' of the wider social network of the person with dementia. For example, the use of a picture button telephone assisted a person with dementia in longer instances of interaction and maintaining social contacts with neighbours, friends and family.

Freedom and autonomy Some of the studies reported carers having to use controlling methods such as locking and restricting access and the AT seemed to offer an alternative solution of enabling the person living with dementia to become independent and participate in meaningful activities. This in turn had a positive effect on the carers. The AT also provided carers with additional personal time which was highly valued and, in many instances, helped create the balance between their own personal space and independence with that of staying connected with the person with dementia.

Safety Carers viewed someone who has dementia's ability to stay in the community and their physical safety as more important than privacy and autonomy. Tracking devices that supported safety were enthusiastically received and AT provided carer reassurance and enhanced independence for both the carer and the person with dementia.

Quality of life Whether the person living with dementia used the AT independently or the carer assisted them, 
Table 2 Types and uses of Assistive Technology

\begin{tabular}{ll}
\hline Main Use & Type of Assistive Technology \\
\hline Basic Activities of Daily Living & Assistive robot - 'Ed' - personal computer; microphones, LCD screen, speakers and \\
& web cameras [51]; Robotic assistants [76, 83] \\
Leisure and social interaction & Special remote control [58]/ Simple remote control to TV [48, 50, 64] \\
& Wearable sensors [71] \\
& Robotic Therapy 'seal' [67] \\
& Talking cazette/magazine [58] \\
& Telephones: \\
& Picture button telephone [46, 58, 75]/ Simple mobile phone $[10,48,50,69] /$ Photo \\
& memory telephone [47]/Easy to use telephone [79] \\
& Tablet computer [42, 70, 80] /MP3 player [89]
\end{tabular}

Memory support

Memory support and Orientation

Memory support; Orientation; MeDose watch [57]

Safety and security

Orientation; Safety and security

Safety and security

Memory aid [58, 88]/Memory games [87]/Information on village they live in [87]/ Cognitive stimulation exercises [88]

Memory Message $[48,57]$

Timer to coffee machine $[48,50]$

Locators:

Object locator [50]/ Lost item locator [35, 46, 75]/Locating technologies [81]

Forget-Me-Not Calendar [57]

Message box connected to coffee machine [50]

Information retrieval system [63]

Reminiscence tools $[10,69]$

Clocks and calendars:

Electronic orientation clocks [10, 69]/ Night and Day Calendar [46, 48, 57, 75, 85]/ automatic day and date calendar [48]/automatic calendar [49, 50]/ Digital calendar with remote control [50]/ Memory clock [48, 50]/

Integrated Rosetta system: Elderly Day Navigator + The early Detection System + Unattended autonomous surveillance system [90]

Assisted cognition system - touchscreen reminders for the day, current date and time, tracking [91]

Smart home management system (Xanboo) [38]/Smart home technologies [76]

Personalised recorded messages [72]

Medicine reminders:

Electronic medication reminder $[46,47,75,88]$; electronic pill dispensers $[10,35$, $59,69,82] /$ Medicine dispenser with alarm [48, 50]/Medication organiser [81]

COGKNOW day navigator - sensors and sensor network $[65,86]$

Talking motion sensors [72]

Product Availability

Research prototype

Commercial Product

Commercial Product

Commercial Product

Commercial Product

Commercial Product

Commercial Product

Research prototype

Commercial Product

Research prototype

Commercial Product

Commercial Product

Research prototype

Commercial Product

Research prototype

Commercial Product

Commercial Product

Research Prototype

Research Prototype

Commercial Product

Commercial Product

Commercial Product

Research prototype

Commercial Product

Commercial Product

Commercial Product

Commercial Product

Commercial Product

Commercial Product

Passage sensor [58]/Sensors [38, 39, 48, 63, 88]/Movement detectors [41, 47]/ Movement sensors [35, 81]/Proximity alarms [81]/Fall sensor [76]

Global Positioning Systems:

Electronic tracking device [58]/ GPS [50, 59, 78, 92]/ GPS Location monitoring devices $[10,66,69,84] /$ Tracking devices $[41,48,76] /$ GPS Tracking system [52, $54-56,67,74,77]$

Stove timer [50, 53]/ Cooker alarm [48]/Gas cooker device [46, 75]/ Automatic gas switch off devices [41]/Cooker monitors [58]

Electronic door lock [48, 50]/Touchpad key locks [81]
Commercial Product/Research prototype

Commercial Product

Commercial Product 
Table 2 Types and uses of Assistive Technology (Continued)

\begin{tabular}{lll}
\hline Main Use & Type of Assistive Technology & Product Availability \\
\hline & Talking wrist watch [48, 50] & Commercial Product \\
& ADLife - gateway with alarm button, sensors [61] & Research prototype \\
& In-home night time monitoring system [36, 37, 40] & Research prototype \\
& Automatic night lamp [46, 75] & Commercial Product \\
& Automatic water switch off devices [41]/Water detector alerts [81] & Commercial Product \\
& Baby monitors [68, 72] & Commercial Product \\
& Health monitoring system [67] & Commercial Product \\
Safety and security, Social & Emergency response system [39, 88]/Emergency transmitters [79] & Commercial Product \\
interaction & Skype (on computer/tablet PC) [68]; Social contact system [67] & Commercial Product \\
& NOCTURNAL - Sensors, communication devices, tablet PC [60] & Research prototype \\
& Cameras [35, 41, 47, 68, 72, 81]/Video communication system [63, 76, 87, 88]/Nideo & Commercial Product \\
\hline
\end{tabular}

AT was perceived as removing worries and burden and generally improved mental well-being, especially when the carer was living away from the person with dementia.

Competence AT was perceived as improving independence for someone who has dementia, this had a positive effect on the carer, with some carers also reporting benefitting from using the AT themselves, such as the simple remote control for TV and memory aids.

\section{Negative aspects}

While the overall experience of AT use was perceived as positive by carers, some important negative aspects were also raised.

Relationships When AT failed or the person living with dementia was no longer able to use the AT, this invariably caused constraints in the relationship, as an outcome of the presence of the AT. Some carers also perceived that the AT would replace the 'person' component of caring.

Freedom and autonomy There were perceptions that the person living with dementia's declining abilities could be further worsened using AT as they would no longer be actively challenged cognitively. Carers also believed that with the people with dementia who did not have adequate social care could be left alone with the technology without additional support for autonomy or social contact.

Competence Carers seemed to be more willing to use AT in the future rather than currently. Elderly carers also worried about their competence and familiarity with AT, especially when there were technical failings with the AT or when the devices required to be replaced with new AT, as the illness progressed.

Quality of life Occasionally, the use of AT seemed to create more dependence of the person with dementia on the carer, which led to increased stress for the carer, and the attitude of the person living with dementia towards the AT (from hostility to indifference) also led to additional carer burden, while choosing and using the AT.

\section{Use of the AT}

Ethical issues Carers weighed the needs of personal reassurance and sense of security with that of autonomy of someone who has dementia while deciding on use of AT. Often there was no perceived ethical dilemma where the safety of the person with dementia was concerned. There was a consensus among carers that people with dementia must be involved as much as possible to select and use AT. Ethical issues around who held the power of choice of usage and discontinuance of AT and whether the needs of the person living with dementia were altered to match the potential of the currently available AT also seem to arise from the studies with no definitive conclusions.

Help and support from carers Carers continuous engagement and willingness to provide support with the use of AT for the person with dementia was key in the use of AT in most of the studies. The carers' attitude, commitment and willingness to learn about the AT were vital if the equipment was to be useful and functional.

Raising issues of using AT Carers used different methods to convince people with dementia to accept and use AT, especially when the person living with dementia was hostile towards or did not understand the 
Table 3 Reported changes in informal carers

\begin{tabular}{|c|c|}
\hline Studies & Positive change \\
\hline Gitlin LN et al. [35] & $\begin{array}{l}\text { Overall somewhat to very } \\
\text { helpful. }\end{array}$ \\
\hline Rowe MA et al. [36] & $\begin{array}{l}\text { - Experimental group } 85 \% \\
\text { less likely to sustain an } \\
\text { event. } \\
\text { - Caregivers reported } \\
\text { satisfaction and confidence } \\
\text { in preventing night time } \\
\text { injuries and exit using the } \\
\text { NMS. }\end{array}$ \\
\hline
\end{tabular}

Rowe MA et al. [37]

Negative change No change Statistically significant
change

\begin{tabular}{|c|c|}
\hline Olsson A et al. [73] & $\begin{array}{l}\text { - Decreased level of worry } \\
\text { about PwD's independen } \\
\text { outdoor activities. }\end{array}$ \\
\hline Pot AM et al. [74] & $\begin{array}{l}\text { - Decrease in the feelings } \\
\text { worry when they could } \\
\text { reach PwD. } \\
\text { - } 30 \% \text { of carers reported } \\
\text { they got time for other } \\
\text { things since using the GP }\end{array}$ \\
\hline Kinney JM et al. [38] & $\begin{array}{l}\text { - } 87.5 \% \text { of carers reported } \\
\text { that the monitoring syste } \\
\text { made life easier (peace of } \\
\text { mind, added security, } \\
\text { easier to keep track of } \\
\text { PwD). } \\
\text { - } 68.75 \% \text { report that the } \\
\text { system gave carers more } \\
\text { free time and more time } \\
\text { for self. }\end{array}$ \\
\hline $\begin{array}{l}\text { Duff P et al. [75] } \\
2007\end{array}$ & $\begin{array}{l}\text { - Carer burden decreased } \\
\text { very slightly during the } \\
\text { course of the trial. } \\
\text { - } 100 \% \text { of carers using } \\
\text { picture telephone and } \\
\text { cooker monitor reported } \\
\text { satisfaction. } \\
\text { - Over } 75 \% \text { of carers } \\
\text { reported satisfaction with } \\
\text { other AT used in the trial. }\end{array}$ \\
\hline Rialle V et al. [76] & $\begin{array}{l}\text { - Tracking devices were } \\
\text { better appreciated by } \\
\text { women. } \\
\text { - Younger caregivers found } \\
\text { AT more useful than } \\
\text { elderly. }\end{array}$ \\
\hline Landau R et al. [77] & $\begin{array}{l}\text { - GPS device used for sake } \\
\text { of patients' safety or for } \\
\text { carers' peace of mind. }\end{array}$ \\
\hline Chen Y-C et al. [78] & $\begin{array}{l}\text { - Most caregivers hope } \\
\text { technological products } \\
\text { (lost seeking devices) } \\
\text { would increase the } \\
\text { efficiency and safety }\end{array}$ \\
\hline
\end{tabular}

Alwin J et al. [79]

- $43.75 \%$ of carers report that the system made life more difficult (cell phone alerts can be annoying; one more thing to worry about)
- No significant improvement in sleep for caregivers.

- NMS not sufficient as standalone treatment

- No significant changes in perceived well-being and burden.

- Feelings of role-overload were not significantly reduced during the study period.
- AT for time orientation, day Carers receiving alarm/ planning and memory devices were more frequently associated with


Table 3 Reported changes in informal carers (Continued)

\begin{tabular}{ll}
\hline Studies & Positive change \\
\hline & \\
& \\
Lim F S et al. [80] & $\begin{array}{l}\text {. } 47.63 \% \text { of carers reported } \\
\text { AT (iPad) was helpful }\end{array}$ \\
McKenzie B et al. [81] & $\begin{array}{l}\text { • AT devices provided } \\
\text { immediate relief, reduce } \\
\text { stress and helped carers } \\
\text { provide care more easily } \\
\text { and safely. }\end{array}$
\end{tabular}

Schulz R et al. [39]

Negative change
No change

group of carers who

reported some/no

significant fulfilment and

importance.

\author{
- Caregivers balance costs \\ against potential benefits \\ such as improved \\ functioning, increased \\ autonomy, reduced \\ burden, better health and \\ enhanced safety.
}

Statistically significant change

\section{Kamimura T [82] \\ - Three caregivers \\ maintained score of little burden or less and one caregiver had a score of mild burden throughout.}

Korchut A et al. [83]

\author{
- Reminders for medication \\ was a high priority. \\ - Carers viewed robotic \\ technology positively.
}

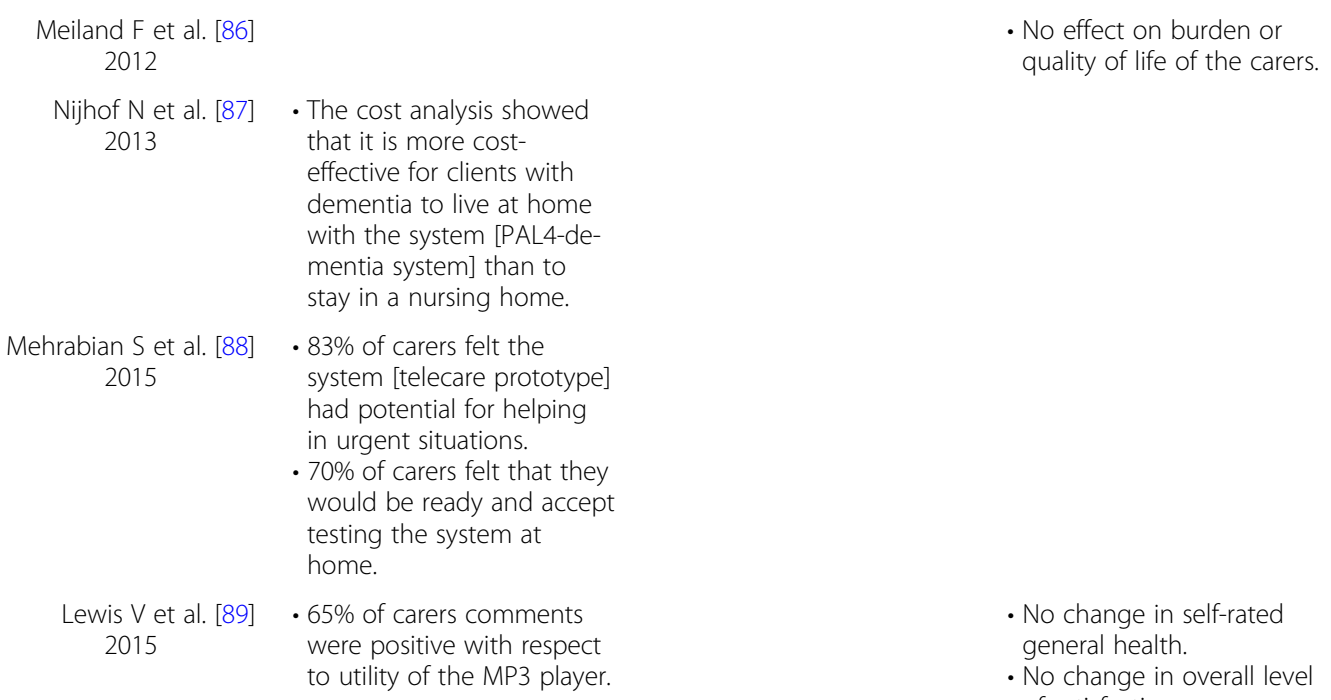

\section{- No effect on burden or} quality of life of the carers.

- Significant increase in the total Symptom

Management Self-Efficacy score (a measure how confident the caregiver is that they will be able to manage problems that come up and deal with the frustrations of caring). Mean at baseline was 23.5 $(S D=6.1)$ and 27.0 after 4 weeks $(S D=7.5)(t=-3.1$, $\mathrm{df}=47, p<0.01)$ 
Table 3 Reported changes in informal carers (Continued)

\begin{tabular}{|c|c|c|c|c|}
\hline Studies & Positive change & Negative change & No change & $\begin{array}{l}\text { Statistically significant } \\
\text { change }\end{array}$ \\
\hline $\begin{array}{c}\text { Hattink B J et al. [90] } \\
2016\end{array}$ & $\begin{array}{l}\text { - All informal carers felt the } \\
\text { system [Rosetta] despite } \\
\text { technical difficulties, is very } \\
\text { useful and that they were } \\
\text { happy with it. }\end{array}$ & & $\begin{array}{l}\text { - No significant differences } \\
\text { on quality of life, perceived } \\
\text { autonomy and feeling of } \\
\text { competence between } \\
\text { participants who used the } \\
\text { Rosetta system and those } \\
\text { who received usual care } \\
\text { (the control group). }\end{array}$ & \\
\hline $\begin{array}{c}\text { Navarro R F et al. [91] } \\
2016\end{array}$ & $\begin{array}{l}\text { - Caregiver burden levels } \\
\text { show a decreasing trend, } \\
\text { while levels of self-efficacy } \\
\text { in caregivers increased by } \\
\text { using the ambient assisted } \\
\text { intervention system. }\end{array}$ & & & \\
\hline $\begin{array}{l}\text { Liu L et al. [92] } \\
2017\end{array}$ & & $\begin{array}{l}\text { - Some problems relate to } \\
\text { false alarms and } \\
\text { notifications. }\end{array}$ & & \\
\hline $\begin{array}{l}\text { Tyack C et al. [42] } \\
2017\end{array}$ & & & $\begin{array}{l}\text { - No significant change of } \\
\text { quality of life or well-being } \\
\text { across the intervention } \\
\text { [tablet computer]. }\end{array}$ & \\
\hline
\end{tabular}

need to use the AT. Carers especially had difficulty convincing someone who has dementia where monitoring and safety devices were to be used compared to using AT for leisure and social interaction.

\section{Acceptance and knowledge of AT}

Costs and resource Carers noted that AT was generally expensive, however most of the studies included in this review either provided the technology to the participants or participants did not mind spending the extra costs for AT that could support the person with dementia to stay for longer, in their own home.

Acceptance of AT Many of the carers accepted AT as useful and their adoption depended on the perceived usefulness of the AT. They would also recommend its use to other carers and people with dementia. Carers also saw technological innovations as inevitable and expected the use of AT to increase and future generations of carers would have better skills and motivation to adopt them.

Knowledge of technology There was a general feeling among carers that information regarding AT should be provided early in the process of diagnosis and support available to the person living with dementia, especially as the progress of dementia was unpredictable. The main need of information was on simple and practical AT solutions with most carers unaware of new AT devices and solutions available.

\section{Discussion}

The aim of this systematic review is to identify the types and uses of assistive technology in dementia and describe the effectiveness and experience of its use for carers. The studies included cover the last 18 years and give a broad picture of AT use in dementia care. Caregiving for people with dementia in the community is usually unplanned, unpaid work carried out by the relative of the person living with dementia. The role of carer can be rewarding, but it can also be detrimental to a person's well-being and can put them under a lot of stress [100, 101], especially for a carer who has little experience. AT is one way for supporting people with dementia and their carers to stay for longer in the community.

The symptoms which have the highest impact on carers of persons with dementia are repetitive questions, apathy, getting lost, aggression and incontinence [37, 40, 66] but the AT solutions from studies included in this review did not effectively address behavioural problems except safety/alert devices for wandering and getting lost. Fuhrer et al. [102] argue that effectiveness, efficiency, device satisfaction, psychological functioning and subjective wellbeing are essential outcomes for continued short-term and long-term use for AT. Findings from this review highlight that carers of people with dementia may prefer a specific type of AT, such as a GPS tracker, movement sensor or medication reminder and perceive it as useful but it may not have any real effect on outcomes of burden, satisfaction or wellbeing, similar to findings from other reviews on AT $[27,103]$. One reason for this could be that existing outcome measures that 
Table 4 Sample quotes for Themes and Sub-themes

\begin{tabular}{lll}
\hline Theme & Sub theme & Example Quotation 1 \\
\hline Positive aspects & Relationships & 'the use of the device generates \\
longer instances of interaction' \\
{$[70]$.}
\end{tabular}

Quality of life (stress, burden, wellbeing)

Competence

Negative aspects Freedom and autonomy

Relationships

Competence

Quality of life (Stress, burden, wellbeing) 'speaking watches" that read the time of day aloud at the push of a button. With this device, the caregivers experienced fewer questions and less stress and misunderstandings about the time' [50].

'it [GPS tracking device] was used to enable the person to continue to go out alone' [56].

'Some participants feared that technology which simplified tasks too much might weaken a person's own abilities such as in remembering numerical series and codes' [59].

'I think people need people - not just gadgets, you know? That's the worrying thing really, with the elderly in particular. The gadgets replace people, and there isn't any comparison' [41].

'Future willingness to use a technology generally outstripped their current willingness to use it' [67].

'Adding activities into the [electronic] calendar was extremely time-consuming and complicated compared to an ordinary calendar: "I cannot sit here evening after evening and
Example Quotation 2

Example Quotation 3

'Technology itself can become a 'member' of the social network, making it stronger' [47].

In this way, the picture phone helped the person with dementia maintain independence, something the relatives described as important' [58].

'simple movement sensors or alarm systems that are networked to allow remote alerts were the most enthusiastically received' [41].

The family caregivers were satisfied because the SRC [Simple Remote Control] removed both worries and burden of interruptions at work' [64].

'enabled them to better balance their needs for personal space with their desires to remain connected to the PWD during the night' [40].

'You can trust another person, but I think technology would be a bit ... well, what if the technology went wrong? You can't be 100\% sure that the person would be cared for when you walk out of the door, can you? If somebody else is there, then you know' [41].

'The simple remote control used to be a great advantage for my wife, but now, after being at the hospital for some weeks, she doesn't know how to operate it any longer. I have to tell her how to use it, all the time, and she is no longer able to use it when she's alone' [50].

'As she was not competent in informatics, Mrs. B. had to rely on the personal care attendant: "She logs very easily and communicates information to me". Thus, the situation was not under Mrs. B.'s control' [54].

'One of the caregivers reported that in some circumstances the system might increase the burden of care, if the sensors detected certain situations where additional care was
I believe that my ability to have my mother continue to live with us would be dramatically reduced if we didn't have NMS' [40].

'Informal caregivers, in contrast [to formal carers], request ICT solutions that enhance their personal freedom' [63].

'Family caregivers expressed the belief that electronic tracking enables the patients' independent outdoor mobility and at the same time improves their safety' [55].

'Informal caregivers reported that use of the system [preventative sensor technology] provided benefits to their mental well-being' [61].

'For the caregiver, data shows that the picture-button telephone was also most useful, with five out of six caregivers claiming they themselves were still using the product 3 months after its installation, and each reporting they considered it useful' [46].

'Mrs B. pointed out the obligation to subscribe to an assistance platform. Mrs. B. would like to have the possibility to buy the device and manage by herself her husband's wandering' [54].

We don't want technology we want people' [41].

'.....equipment may need some adjustments for use by elderly caregivers' [52].

'...family members were not sure how to raise the issue of using an electronic tracking device: "How do you explain [to] your relatives that they will be monitored in all their 
Table 4 Sample quotes for Themes and Sub-themes (Continued)

\begin{tabular}{|c|c|c|c|c|}
\hline Theme & Sub theme & Example Quotation 1 & Example Quotation 2 & Example Quotation 3 \\
\hline & & struggle with this computer!' [50]. & required' [61]. & outdoor activities?' [55]. \\
\hline \multirow[t]{3}{*}{ Use of AT } & Ethical issues & $\begin{array}{l}\text { 'The persons with dementia and } \\
\text { their spouses saw the value of } \\
\text { being locatable and saw no } \\
\text { problem with the persons with } \\
\text { dementia being monitored; they } \\
\text { had not even considered that } \\
\text { aspect' [62]. }\end{array}$ & $\begin{array}{l}\text { 'Among the most central } \\
\text { worries were fears of a } \\
\text { dehumanized care' [63]. }\end{array}$ & $\begin{array}{l}\text { '... relatives shifted between } \\
\text { their own needs for safety and } \\
\text { security and what they } \\
\text { perceived to be the need of the } \\
\text { person with dementia when } \\
\text { reflecting on the use of ICT' [58]. }\end{array}$ \\
\hline & $\begin{array}{l}\text { Help and support } \\
\text { from carers }\end{array}$ & $\begin{array}{l}\text { 'The engagement and interest of } \\
\text { FC [Family Carers] was crucial in } \\
\text { order to follow up the new AT } \\
\text { device and support the person } \\
\text { with YOD in using it' [50]. }\end{array}$ & $\begin{array}{l}\text { 'Carers provide practical help } \\
\text { that involves cognitive effort } \\
\text { and is emotionally challenging' } \\
\text { [49]. }\end{array}$ & $\begin{array}{l}\text { 'the use of assistive technology } \\
\text { was in some cases influenced } \\
\text { by the availability of a caregiver } \\
\text { willing to remind the person } \\
\text { about the product' [46]. }\end{array}$ \\
\hline & $\begin{array}{l}\text { Raising issues of } \\
\text { using AT }\end{array}$ & $\begin{array}{l}\text { 'She said she felt, it (a pendant } \\
\text { alarm) made her feel like a crock, } \\
\text { you know (laughing). She says, "I } \\
\text { don't need this, I'm perfectly } \\
\text { alright." And the way that I } \\
\text { persuaded her to wear it was, I } \\
\text { said, "It just makes me feel better } \\
\text { to know that you can contact } \\
\text { somebody if you have a fall in } \\
\text { the house, or if you're not too }\end{array}$ & $\begin{array}{l}\text { 'The carers' attitude, } \\
\text { commitment and will to learn } \\
\text { about and follow through with } \\
\text { the testing of the technology } \\
\text { were vital if the equipment was } \\
\text { to be useful and functional' [48]. }\end{array}$ & $\begin{array}{l}\text { 'One participant had adjusted } \\
\text { their newly purchased washing } \\
\text { machine by labelling each } \\
\text { compartment of the machine so } \\
\text { that his wife would know where } \\
\text { to put the washing detergent } \\
\text { and the rinsing agent, thus } \\
\text { enabling her to "still be ruler of } \\
\text { the laundry room," as he put it' } \\
\text { [59]. }\end{array}$ \\
\hline
\end{tabular}

Acceptance and knowledge of AT

Costs and resources

Acceptance of AT

Knowledge of Technology
The participants saw technological innovations as an intrinsic feature of societal change and inevitable. The expectation was that the use of technology would increase, particularly for the next generation of carers who would have the aptitude and skills to adopt them' [41].

'Carers and GPs generally found the term AT unhelpful and open to interpretation...... "Well, I think the whole thing was introduced to me in a very nebulous way. Technology, what the hell does that mean?"' [69].
'Several carers noted that AT was generally expensive. You know, some people can't afford it. I don't mind paying for it 'cause it's helping her (mother) but I think it, it is expensive. It is quite steep, but then again, if her attendance money is there for it and she needs it, you, you don't mind getting it if it's going to help her, you know' [10].

'One prerequisite for incorporation of technology emphasized in all groups was that technology must not be perceived as stigmatizing by the prospective user' [59].

Timely information is important for the FC, because the AT may become too complicated to handle for the person with YOD, as the dementia progresses' [50].
'... when the participants considered technology to be beneficial to their relative with dementia or to themselves in their roles as significant others, they were ready to try technological solutions for support' [59].

'..the use and usefulness of the five products tested was largely determined by their technical capacity' [46].
'Dementia caregivers' knowledge of new technologies lags behind current technology development' [67]. are being used in AT studies may not be sensitive enough to measure change when using AT or are not valid in this context, perhaps as most measures were developed before AT was introduced.
This review highlights the continued lack of consistency in describing or classifying AT [104]. Other studies and reviews [7, 102, 105-107] have highlighted different ways of classifying AT used in dementia care. Having a 
classification system based on use (with more than one use per AT) from the perspective of the person with dementia and carer, as described in this review, may improve consistency of reporting and enhance synthesis of findings from trials and reviews. We have classified AT based on (i) Name of AT (ii) Type of AT (iii) function assisted (use or intended impact) and (iv) availability (commercial/ prototype).

Though some research, involving robotic technology in institutional and simulation/lab based settings is looking into this $[108,109]$, this review identified the lack of sufficient number of AT to support basic and instrumental Activities of Daily Living for people living with dementia at home. This could be because it is difficult to develop and deploy potentially bulky/expensive AT in a non-institutional setting or perhaps human/assisted care is seen as easier and less expensive way of providing this care [110]. It is also possible that technological advances in miniaturisation and artificial intelligence have not yet caught up with this area of need.

It is also clear from this review that installation of AT at home for use by someone who has dementia was often wrongly seen as a one-off event, rather than an ongoing process for getting the best out of AT. Similar to other findings [111-114], this review found that carers as users of AT often struggle to understand and engage with the technology in their homes as a result of poor understanding, a lack of knowledge of available AT and lack of on-going support from professionals and design flaws in the AT itself.

The review also highlights the perceived fear among some carers that use of AT could lead to social isolation. However available AT solutions such as tablet computers and monitoring devices to alert carers gives them a sense of participating in the life of a person living with dementia even when the carer is not physically present, this led to AT being viewed as a positive addition. There was no evidence within the included studies that multiple AT solutions were being harnessed to bring them together for an integrated solution that could assist both people with dementia and carers. AT devices were used in isolation for specific functions rather than a combined use of the devices. With the rise of internet of things $[115,116]$ and connected AT devices combining multiple AT for use with a person with dementia or carer is feasible and in most instances more desirable [117].

Interestingly all the studies considered the introduction of AT after a diagnosis of dementia, the timing of introducing devices may be important. Safety/tracking devices were introduced pre-emptively to prevent secondary problems $[7,27]$ such as falls and wandering, which in turn could potentially reduce admissions into long-term care [118] but equal consideration and further research may be needed for the use of AT as a preventative measure especially in areas of orientation, memory and leisure.

Many of the installed AT did not meet the needs of the user. Despite a surprising lack of reporting on adverse events, some of the negative reactions to AT were because they were 'Off the shelf' devices and were rarely useful, especially with a progressive condition like dementia. The AT needed to be adapted or customised for the carers and people with dementia's individual needs and when this was not the case, led to abandonment of the AT [117, 119, 120]. Co-creating AT with users has steadily improved over time. Carers need to be involved in the design and testing of AT solutions and in prioritising the problems that need to be addressed to allow AT to be accepted as a solution for caring for people living with dementia in the community [121, 122].

\section{Implications and recommendations from this review}

1. The function assisted domain (e.g. Memory device, GPS tracker) as a way of naming the AT is usually defined by the manufacturer/developer of the AT. We recommend a shift towards considering naming the use of the AT from the perspective of the person with dementia and their carer to ensure that device is appropriately used and can provide the intended benefits of that AT [123] for both the carer and the person living with dementia.

2. Further research should be carried out on how multiple AT devices could work together or be combined to better support someone who has dementia and their carers rather than how individual AT devices can support them.

3. Future research should focus on AT solutions which are co-designed by those with lived experience of the challenges of dementia at home and should include carers, who live with and away from a person with dementia.

4. Ability of a carer to 'problem solve' should be a consideration in AT prescription and use. Technology should match the needs of the person requiring the use of the $\mathrm{AT}$, rather than the person being 'moulded' to match what technology is available for them.

\section{Limitations}

Due to the variety of AT devices and outcome measures used, we could not pool results from the quantitative studies and have provided a narrative review instead. Due to financial constraints we did not include studies in languages other than English within this review and this could have potentially led to some suitable studies 
being missed. However, we did scan for reference lists of all studies that were included for full text review and are confident that this review captures all suitable studies that met our inclusion criteria.

\section{Conclusions}

Technology is advancing at an extremely rapid pace, especially within the fields of artificial intelligence and machine learning with their resultant healthcare applications. It is likely that AT powered by AI may become ubiquitous soon. The quality of research focussing on AT use in dementia continues to be low. AT solutions helps improve carers' experience of providing care to a person living with dementia. AT would support people with dementia and carers in the community but researchers, healthcare professionals and technology developers should adopt a family centred model for use of AT than pursuing only an individual/person centred model of care.

\section{Additional files}

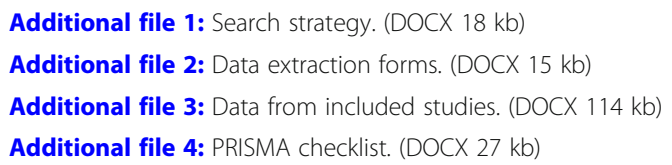

\section{Abbreviations \\ ALOIS: ALOIS, named after Alois Alzheimer, is a register of dementia studies maintained by the Cochrane Dementia and Cognitive Improvement Group; AMED: Allied and Complementary Medicine Database; AT: Assistive technology; CINAHL: Cumulative Index of Nursing and Allied Health Literature; PRISMA: Preferred Reporting Items for Systematic Reviews and Meta-Analyses; PROSPERO: International Prospective Register of Systematic Review}

\section{Acknowledgements}

Authors would like to acknowledge support from Ms. Nia Roberts (Medical library librarian) for help with the search strategy. The authors acknowledge the contribution from the four members of the patient and public engagement and involvement panel set up as part of the carers' experience of assistive technology use in dementia study, for their comments on the review findings, The authors also acknowledge the constructive comments from the reviewers which have helped clarify, refine and strengthen this manuscript.

\section{Authors' contributions}

VS, CJ and MP conceived the design of the study. VS developed the search strategy together with a qualified librarian and conducted the search. VS and MP checked studies for eligibility and CJ resolved any conflicts in study selection. VS drafted the protocol and the draft version of this systematic review with critical revision and input from MP and CJ. All authors have read and given approval for this version. VS is the guarantor of the review.

\section{Authors' information}

VS is a postgraduate student registered for his DPhil at the University of Oxford exploring informal carers' experience of assistive technology use in dementia. MP is an Associate Professor within the Health Services Research Unit (HSRU), Nuffield Department of Population Health, University of Oxford. CJ is Professor of Health Services Research and Director of the HSRU, Nuffield Department of Population Health, University of Oxford. MP and CJ are joint supervisors of VS for the DPhil.

\section{Funding}

This systematic review is part of a DPhil in Population Health at the University of Oxford.

\section{Availability of data and materials}

All data generated or analysed during this study are included in this published article [and its supplementary information files].

Ethics approval and consent to participate

Not applicable.

\section{Consent for publication}

Not applicable.

\section{Competing interests}

The authors declare that they have no competing interests.

Received: 22 February 2019 Accepted: 23 May 2019

Published online: 14 June 2019

\section{References}

1. World Health Organisation. ICD-11 - mortality and morbidity statistics: World Health Organisation; 2018. https://icd.who.int/browse11/l-m/en. Accessed 30 Aug 2018

2. World Health Organisation. Dementia. Key facts: World Health Organisation Key facts; 2017. http://www.who.int/news-room/fact-sheets/detail/dementia. Accessed 30 Aug 2018

3. Banerjee S, Murray J, Foley B, Atkins L, Schneider J. Predictors of institutionalisation in people with dementia. J Neurol Neurosurg Psychiatry. 2003;74:1315-6. https://doi.org/10.1136/jnnp.74.9.1315.

4. Prince M, Wimo A, Guerchet M, Ali G-C, Wu Y-T, Prina M, et al. The global impact of dementia: an analysis of prevalence, incidence, cost and trends. London; 2015. https://doi.org/10.1111/j.0963-7214.2004.00293.x.

5. Prince M, Knapp M, Guerchet M, McCrone P, Prina M, Comas-Herrera A, et al. Dementia UK: update second edition. London; 2014. https://www. alzheimers.org.uk/download/downloads/id/2323/dementia_uk_update.pdf. Accessed 27 Nov 2017

6. National Collaborating Centre for Mental Health. The dementia care pathway. Full implementation guidance. London; 2018. https://www. rcpsych.ac.uk/docs/default-source/improving-care/nccmh/nccmh-dementiacare-pathway-full-implementation-guidance.pdf?sfvrsn=cdef189d_6. Accessed 30 Aug 2018.

7. Daly Lynn J, Rondón-Sulbarán J, Quinn E, Ryan A, McCormack B, Martin S. A systematic review of electronic assistive technology within supporting living environments for people with dementia. Dementia. 2017:147130121773364. https://doi.org/10.1177/1471301217733649.

8. Woolham J, Gibson G, Clarke P. Assistive technology, telecare, and dementia: some implications of current policies and guidance. Res Policy Plan. 2006;24:149-64 http://ssrg.org.uk/wp-content/uploads/2012/02/ rpp243/p19p34.pdf. Accessed 4 Dec 2017.

9. Gibson G, Newton L, Pritchard G, Finch T, Brittain K, Robinson L. The provision of assistive technology products and services for people with dementia in the United Kingdom. Dementia. 2014;15:681-701. https://doi. org/10.1177/1471301214532643.

10. Gibson G, Dickinson C, Brittain K, Robinson L. The everyday use of assistive technology by people with dementia and their family carers: a qualitative study. BMC Geriatr. 2015;15:89. https://doi.org/10.1186/s12877-015-0091-3.

11. Boyd H, Evans N, Cheston R, Noonan K, Harris N. Home testing of a digital prompter for people with dementia. Stud Health Technol Inform. 2017;242: 27-30 http://www.ncbi.nlm.nih.gov/pubmed/28873772. Accessed 27 Oct 2017.

12. The Audit commission. Assistive technology. London; 2004. http://www wales.nhs.uk/documents/National20Report_FINAL.pdf. Accessed $27 \mathrm{Nov}$ 2017

13. AKTIVE Consortium. The role of telecare in meeting the care needs of older people themes, debates and perspectives in the literature on ageing and technology. Leeds; 2013. www.aktive.org.uk/publications.html. Accessed 27 Nov 2017

14. Bledsoe LK, Moore SE, Collins WL, Bledsoe LK, Moore SE, Collins WL, et al. Long distance caregiving: an evaluative review of the literature context for 
provision of care from a distance. Ageing Int. 2010;35:293-310. https://doi. org/10.1007/s12126-010-9062-3.

15. Czaja SJ, Rubert MP. Telecommunications technology as an aid to family caregivers of persons with Dementia. Psychosom Med. 2002;64:469-76. https://doi.org/10.1097/00006842-200205000-00011.

16. McKechnie V, Barker C, Stott J. Effectiveness of computer-mediated interventions for informal carers of people with dementia-a systematic review. Int Psychogeriatr. 2014;26:1619-37. https://doi.org/10.1017/ S1041610214001045.

17. Jeong J-S, Kim Y, Chon M-G. Who is caring for the caregiver? The role of cybercoping for dementia caregivers. Health Commun. 2018;33:5-13. https://doi.org/10.1080/10410236.2016.1242030.

18. Tyack C, Camic PM. Touchscreen interventions and the well-being of people with dementia and caregivers: a systematic review. Int Psychogeriatr. 2017; 29:1261-80. https://doi.org/10.1017/S1041610217000667.

19. Huschilt J, Clune L. The use of socially assistive robots for dementia care. J Gerontol Nurs. 2012;38:15-9. https://doi.org/10.3928/00989134-20120911-02.

20. Fleming R, Sum S. Empirical studies on the effectiveness of assistive technology in the care of people with dementia: a systematic review. J Assist Technol. 2014;8:14-34. https://doi.org/10.1108/JAT-09-2012-0021.

21. Kang HG, Mahoney DF, Hoenig H, Hirth VA, Bonato P, Hajjar I, et al. In situ monitoring of health in older adults: technologies and issues. J Am Geriatr Soc. 2010;58:1579-86. https://doi.org/10.1111/j.1532-5415.2010.02959.x.

22. Kamel Boulos MN, Lou RC, Anastasiou A, Nugent CD, Alexandersson J, Zimmermann G, et al. Connectivity for healthcare and well-being management: examples from six European projects. Int J Environ Res Public Health. 2009;6:1947-71. https://doi.org/10.3390/ijerph6071947.

23. Mahoney DF, Purtilo RB, Webbe FM, Alwan M, Bharucha AJ, Adlam TD, et al. In-home monitoring of persons with dementia: ethical guidelines for technology research and development. Alzheimers Dement. 2007;3:217-26. https://doi.org/10.1016/J.JALZ.2007.04.388.

24. Bharucha AJ, Anand V, Forlizzi J, Dew MA, Reynolds CF, Stevens S, et al. Intelligent assistive technology applications to dementia care: current capabilities, limitations, and future challenges. Am J Geriatr Psychiatry. 2009: 17:88-104. https://doi.org/10.1097/JGP.0b013e318187dde5.

25. Van der Roest HG, Wenborn J, Pastink C, Dröes R-M, Orrell M. Assistive technology for memory support in dementia. Cochrane Database Syst Rev. 2017. https://doi.org/10.1002/14651858.CD009627.pub2.

26. Gagnon-Roy M, Bourget A, Stocco S, Courchesne A-CL, Kuhne N, Provencher V. Assistive technology addressing safety issues in dementia: a scoping review. Am J Occup Ther. 2017;71:7105190020p1. https://doi.org/10. 5014/ajot.2017.025817.

27. Brims $L$, Oliver K. Effectiveness of assistive technology in improving the safety of people with dementia: a systematic review and meta-analysis. Aging Ment Health. 2018:1-10. https://doi.org/10.1080/13607863.2018.1455805.

28. International Standard Randomised Controlled Trials Number. ISRCTN Registry. https://www.isrctn.com/search?q=. Accessed 19 Jan 2019

29. National Institute of Health. ClinicalTrials.gov. https://clinicaltrials.gov/. Accessed 19 Jan 2019

30. Veritas Health Innovation. Covidence systematic review software. 2017. www.covidence.org.

31. Higgins J, Green S. Cochrane handbook for systematic reviews of interventions version 5.1.0. 2011. http://handbook.cochrane.org.

32. Dixon-Woods M, Agarwal S, Jones D, Young B, Sutton A. Synthesising qualitative and quantitative evidence: a review of possible methods. J Health Serv Res Policy. 2005;10:45-53. https://doi.org/10.1177/ 135581960501000110.

33. Ring NA, Ritchie K, Mandava L, Jepson R. A guide to synthesising qualitative research; 2011. p. 21-3. http://www.healthcareimprovementscotland.org/ programmes/clinical_cost_effectiveness/shtg/synth_qualitative_research. aspx. Accessed 28 Aug 2018

34. Free Reference Manager \& Citation Generator - Mendeley. https://www.mendeley. com/reference-management/reference-manager. Accessed 28 Aug 2018.

35. Gitlin LN, Winter L, Dennis MP. Assistive devices caregivers use and find helpful to manage problem behaviors of dementia. Gerontechnology. 2010; 9:408-14. https://doi.org/10.4017/gt.2010.09.03.006.00.

36. Rowe MA, Annette K, Horne C, Lane S, Campbell J, Lehman B, et al. Reducing dangerous nighttime events in persons with dementia using a nighttime monitoring system. Alzheimers Dement. 2009;5:419-26.

37. Rowe MA, Kairalla JA, McCrae CS. Sleep in dementia caregivers and the effect of a nighttime monitoring system. J Nurs Scholarsh. 2010;42:338-47.
38. Kinney JM, Kart CS, Murdoch LD, Conley CJ. Striving to provide safety assistance for families of elders.the SAFE house project. Dementia. 2004;3:351-70.

39. Schulz R, Beach SR, Matthews JT, Courtney K, De Vito Dabbs A, Mecca LP. Caregivers' willingness to pay for technologies to support caregiving. Gerontologist. 2016;56:817-29.

40. Spring HJ, Rowe MA, Kelly A. Improving caregivers' well-being by using technology to manage nighttime activity in persons with dementia. Res Gerontol Nurs. 2009;2:39-48. https://doi.org/10.3928/19404921-20090101-10.

41. Powell J, Gunn L, Lowe P, Sheehan B, Griffiths F, et al. New networked technologies and carers of people with dementia: an interview study. Ageing Soc. 2010;30:1073-88. https://doi.org/10.1017/S0144686X1000019X.

42. Tyack C, Camic PM, Heron MJ, Hulbert S. Viewing art on a tablet computer: a well-being intervention for people with dementia and their caregivers; 2017.

43. Tractenberg RE, Schafer K, Morris JC. Interobserver disagreements on clinical dementia rating assessment: interpretation and implications for training. Alzheimer Dis Assoc Disord. 15:155-61 https://journals.Iww.com/ alzheimerjournal/Fulltext/2001/07000/Interobserver_Disagreements_on_ Clinical_Dementia.7.aspx. Accessed 3 Oct 2018.

44. Pluye P, Gagnon MP, Griffiths F, Johnson-Lafleur J. A scoring system for appraising mixed methods research, and concomitantly appraising qualitative, quantitative and mixed methods primary studies in mixed studies reviews. Int J Nurs Stud. 2009;46:529-46. https://doi.org/10.1016/j.jijnurstu.2009.01.009.

45. Pluye $\mathrm{P}$, Hong QN. Combining the power of stories and the power of numbers: mixed methods research and mixed studies reviews. Annu Rev Public Health 2014;35:29-45. https://doi.org/10.1146/annurev-publhealth-032013-182440.

46. Cahill S, Begley E, Faulkner JP, Hagen I. Findings from Ireland on the use and usefulness of assistive technology for people with dementia. Technol Disabil. 2007;19(2-3):133-42.

47. Riikonen M, Paavilainen E, Salo H. Factors supporting the use of technology in daily life of home-living people with dementia. Technol Disabil. 2013;25: 233-43. https://doi.org/10.3233/TAD-130393.

48. Arntzen C, Holthe T, Jentoft R. Tracing the successful incorporation of assistive technology into everyday life for younger people with dementia and family carers. Dementia. 2016;15:646-62. https://doi.org/10.1177/ 1471301214532263.

49. Evans N, Collier L. An exploration of the experience of using calendar reminders for people with dementia and family carers. Dementia. 2017: 1471301217734916. https://doi.org/10.1177/1471301217734916.

50. Holthe T, Jentoft R, Arntzen C, Thorsen K. Benefits and burdens: family caregivers' experiences of assistive technology (AT) in everyday life with persons with young-onset dementia (YOD). Disabil Rehabil Assist Technol. 2017:1-9. https://doi.org/10.1080/17483107.2017.1373151.

51. Wang RH, Sudhama A, Begum M, Huq R, Mihailidis A. Robots to assist daily activities: views of older adults with Alzheimer's disease and their caregivers. Int Psychogeriatr. 2017;29:67-79.

52. Altus DE, Mathews RM, Xaverius PK, Engelman KK, Nolan BAD. Evaluating an electronic monitoring system for people who wander. Am J Alzheimers Dis. 2000;15:121-5.

53. Starkhammar S, Nygard L. Using a timer device for the stove: experiences of older adults with memory impairment or dementia and their families. Technol Disabil. 2008;20:179-91 https://content.iospress.com/articles/ technology-and-disability/tad00257.

54. Faucounau V, Riguet M, Orvoen G, Lacombe A, Rialle V, Extra J, et al. Electronic tracking system and wandering in Alzheimer's disease: a case study. Ann Phys Rehabil Med. 2009;52:579-87. https://doi.org/10.1016/.j.rehab.2009.07.034.

55. Landau R, Auslander GK, Werner S, Shoval N, Heinik J. Families and professional caregivers views of using advanced technology to track people with dementia. Qual Health Res. 2010;20:409-19.

56. White EB, Montgomeiy P, McShane R. Electronic tracking for people with dementia who get lost outside the home: a study of the experience of familial carers. Br J Occup Ther. 2010;73:152-9.

57. Rosenberg L, Nygård L, Nygard L. Persons with dementia become users of assistive technology: a study of the process. Dementia. 2011;11:135-54. https://doi.org/10.1177/1471301211421257.

58. Olsson A, Engström M, Skovdahl K, Lampic C. My, your and our needs for safety and security: relatives' reflections on using information and communication technology in dementia care. Scand J Caring Sci. 2012;26: 104-12. https://doi.org/10.1111/j.1471-6712.2011.00916.x.

59. Rosenberg L, Kottorp A, Nygård L, Nygard L. Readiness for technology use with people with Dementia: the perspectives of significant others. J Appl Gerontol. 2011;31:510-30. https://doi.org/10.1177/0733464810396873. 
60. Martin S, Augusto JC, Mccullagh P, Carswell W, Zheng H, Wang H, et al. Participatory research to design a novel telehealth system to support the night-time needs of people with dementia: NOCTURNAL. Int J Environ Res Public Health. 2013;10:6764-82.

61. Nijhof N, van Gemert-Pijnen LJ, Woolrych R, Sixsmith A. An evaluation of preventive sensor technology for dementia care. J Telemed Telecare. 2013; 19:95-100.

62. Olsson A, Engström M, Lampic C, Skovdahl K. A passive positioning alarm used by persons with dementia and their spouses - a qualitative intervention study. BMC Geriatr. 2013;13:11.

63. Hastall MR, Eiermann ND, Ritterfeld U. Formal and informal carers' views on ICT in dementia care: insights from two qualitative studies. Gerontechnology. 2014;13:53-8

64. Jentoft $R$, Holthe T, Arntzen C. The use of assistive technology in the everyday lives of young people living with dementia and their caregivers. Can a simple remote control make a difference? Int Psychogeriatr. 2014;26: 2011-21. https://doi.org/10.1017/S1041610214001069.

65. Meiland FJM, Hattink BJJ, Overmars-Marx T, de Boer ME, Jedlitschka A, Ebben PWG, et al. Participation of end users in the design of assistive technology for people with mild to severe cognitive problems; the European Rosetta project. Int Psychogeriatr. 2014;26:769-79. https://doi.org/ 10.1017/S1041610214000088

66. Milne H, van der Pol M, McCloughan L, Hanley J, Mead G, Starr J, et al. The use of global positional satellite location in dementia: a feasibility study for a randomised controlled trial. BMC Psychiatry. 2014;14:1-13.

67. Burstein AA, DaDalt O, Kramer B, D'Ambrosio LA, Coughlin JF. Dementia caregivers and technology acceptance: interest outstrips awareness. Gerontechnology. 2015;14:45-56.

68. Grigorovich A, Rittenberg N, Dick T, McCann A, Abbott A, Kmielauskas A, et al. Roles and coping strategies of sons caring for a parent with dementia. Am J Occup Ther. 2016;70:1-9.

69. Newton L, Dickinson C, Gibson G, Brittain K, Robinson L. Exploring the views of GPs, people with dementia and their carers on assistive technology: a qualitative study. BMJ Open. 2016;6:1-8.

70. Ekström A, Ferm U, Samuelsson C. Digital communication support and Alzheimer's disease. Dementia. 2017;16:711-31.

71. Hassan L, Swarbrick C, Sanders C, Parker A, Machin M, Tully MP, et al. Tea, talk and technology: patient and public involvement to improve connected health 'wearables' research in dementia. Res Involv Engagem. 2017;3:12. https://doi.org/10.1186/s40900-017-0063-1.

72. Lorenz K, Freddolino PP, Comas-Herrera A, Knapp M, Damant J. Technologybased tools and services for people with dementia and carers: mapping technology onto the dementia care pathway. Dementia. 2017: 147130121769161. https://doi.org/10.1177/1471301217691617.

73. Olsson A, Engström M, Åsenlöf P, Skovdahl K, Lampic C. Effects of tracking technology on daily life of persons with dementia: three experimental single-case studies. Am J Alzheimers Dis Other Dement. 2015;30:29-40.

74. Pot AM, Willemse BM, Horjus S. A pilot study on the use of tracking technology: feasibility, acceptability, and benefits for people in early stages of dementia and their informal caregivers. Aging Ment Health. 2012;16:127-34.

75. Duff $P$, Dolphin C. Cost-benefit analysis of assistive technology to support independence for people with dementia - part 2: results from employing the ENABLE cost-benefit model in practice. Technol Disabil. 2007;19:79-90.

76. Rialle V, Ollivet C, Guigui C, Hervé C. What do family caregivers of Alzheimer's disease patients desire in smart home technologies? Contrasted results of a wide survey. Methods Inf Med. 2008;47:63-9. https://doi.org/10.3414/ME9102.

77. Landau. Attitudes of family and professional care givers towards the use of GPS for tracking tracking patients with dementia: a exploratory study. British J Soc Work. 2009;39:92-670.

78. Chen $Y-C$, Leung C-Y. Exploring functions of the lost seeking devices for people with dementia. Work. 2012;41:3093-100.

79. Alwin J, Persson J, Krevers B. Perception and significance of an assistive technology intervention - the perspectives of relatives of persons with dementia. Disabil Rehabil. 2013;35:1519-26. https://doi.org/10.3109/ 09638288.2012.743603.

80. Lim FS, Wallace T, Luszcz MA, Reynolds KJ. Usability of tablet computers by people with early-stage dementia. Gerontology. 2012;59:174-82. https://doi. org/10.1159/000343986.

81. McKenzie B, Bowen ME, Keys K, Bulat T. Safe home program: a suite of technologies to support extended home care of persons with dementia.
Am J Alzheimer's Dis Other Demen. 2013;28:348-54. https://doi.org/10.1177/ 1533317513488917.

82. Kamimura T. Older adults with Alzheimer's disease who have used an automatic medication dispenser for 3 or more years. Clin Gerontol. 2017:17. https://doi.org/10.1080/07317115.2017.1347594.

83. Korchut A, Szklener S, Abdelnour C, Tantinya N, Hernández-Farigola J, Ribes $J C$, et al. Challenges for service robots-requirements of elderly adults with cognitive impairments. Front Neurol. 2017;8(Jun):1-12.

84. Megges H, Freiesleben SD, Jankowski N, Haas B, Peters O. Technology for home dementia care: a prototype locating system put to the test. Alzheimer's Dement (New York, N Y). 2017;3:332-8. https://doi.org/10.1016/j. trci.2017.04.004.

85. Topo P, Saarikalle K, Begley E, Cahillb S, Holthe T, Macijauskiene J. "I don't know about the past or the future, but today it's Friday" evaluation of a time aid for people with dementia. Technol Disabil. 2007;19:121-31. https://content.iospress.com/articles/technology-anddisability/tad00234.

86. Meiland FJMM, Bouman AlEE, Sävenstedt S, Bentvelzen S, Davies RJ, Mulvenna MD, et al. Usability of a new electronic assistive device for community-dwelling persons with mild dementia. Aging Ment Health. 2012; 16:584-91. https://doi.org/10.1080/13607863.2011.651433.

87. Nijhof N, van Gemert-Pijnen JEWC, Burns CM, Seydel ER. A personal assistant for dementia to stay at home safe at reduced cost. Gerontechnology. 2013; 11:469-79.

88. Mehrabian S, Extra J, Wu YH, Pino M, Traykov L, Rigaud AS. The perceptions of cognitively impaired patients and their caregivers of a home telecare system. Med Devices Evid Res. 2014;8:21-9.

89. Lewis V, Bauer M, Winbolt M, Chenco C, Hanley F. A study of the effectiveness of MP3 players to support family carers of people living with dementia at home. Int Psychogeriatr. 2015;27:471-9.

90. Hattink BJJ, Meiland FJM, Overmars-Marx T, de Boer M, Ebben PWG, van Blanken M, et al. The electronic, personalizable Rosetta system for dementia care: exploring the user-friendliness, usefulness and impact. Disabil Rehabil Assist Technol. 2016;11(1):61-71.

91. Navarro RF, Rodríguez MD, Favela J. Use and adoption of an assisted cognition system to support therapies for people with dementia. Comput Math Methods Med. 2016;2016:1-10.

92. Liu L, Miguel Cruz A, Ruptash T, Barnard S, Juzwishin D. Acceptance of global positioning system (GPS) technology among dementia clients and family caregivers. J Technol Hum Serv. 2017;35:99-119. https://doi.org/10. 1080/15228835.2016.1266724.

93. Snilstveit B, Oliver S, Vojtkova M. Narrative approaches to systematic review and synthesis of evidence for international development policy and practice. J Dev Eff. 2012;4:409-29. https://doi.org/10.1080/19439342.2012.710641.

94. Crellin NE, Orrell M, McDermott O, Charlesworth G. Self-efficacy and healthrelated quality of life in family carers of people with dementia: a systematic review. Aging Ment Health. 2014;18:954-69. https://doi.org/10.1080/ 13607863.2014.915921.

95. Popay J, Roberts H, Sowden A, Petticrew M, Arai L, Rodgers M, et al. Guidance on the conduct of narrative synthesis in systematic reviews a product from the ESRC methods programme peninsula medical school, universities of Exeter and Plymouth. 2006. http://citeseerx.ist.psu.edu/viewdoc/download?doi=10.1.1. 178.3100\&rep=rep1\&type=pdf. Accessed 20 Sept 2018

96. Lins S, Hayder-Beichel D, Rücker G, Motschall E, Antes G, Meyer G, et al. Efficacy and experiences of telephone counselling for informal carers of people with dementia. Cochrane Database Syst Rev. 2014. https://doi.org/ 10.1002/14651858.CD009126.pub2.

97. Timulak $L$. The SAGE handbook of qualitative data analysis. London: SAGE publications Ltd; 2015. https://uk.sagepub.com/en-gb/eur/the-sagehandbook-of-qualitative-data-analysis/book237405. Accessed 28 Aug 2018

98. NVivo Software downloads | NVivo. http://www.qsrinternational.com/nvivo/ support-overview/downloads. Accessed 28 Aug 2018.

99. AT Dementia. AT Dementia - assistive technology for people with dementia. 2018. https://www.atdementia.org.uk/productSearch.asp?page_id=16. Accessed 30 Aug 2018.

100. Sörensen S, Duberstein P, Gill D, Pinquart M. Dementia care: mental health effects, intervention strategies, and clinical implications. Lancet Neurol. 2006; 5:961-73. https://doi.org/10.1016/S1474-4422(06)70599-3

101. Reinhard SC, Given B, Petlick NH, Bemis A. Supporting family caregivers in providing care: Agency for Healthcare Research and Quality (US); 2008. http://www.ncbi.nlm.nih.gov/pubmed/21328765. Accessed 17 Jan 2019 
102. Fuhrer M, Jutai J, Scherer M, DeRuyter F. A framework for the conceptual modelling of assistive technology device outcomes. Disabil Rehabil. 2003;25: 1243-51. https://doi.org/10.1080/09638280310001596207.

103. Greenwood N, Smith R. The oldest carers: a narrative review and synthesis of the experiences of carers aged over 75 years. Maturitas. 2016;94:161-72. https://doi.org/10.1016/J.MATURITAS.2016.10.001.

104. Martin S, Kelly G, Wg K, Mccreight B, Nugent C, Martin S, et al. Smart home technologies for health and social care support (review). Cochrane Database Syst Rev. 2009. https://doi.org/10.1002/14651858.CD006412.pub2.

105. Godwin KM, Mills WL, Anderson JA, Kunik ME. Technology-driven interventions for caregivers of persons with dementia. Am J Alzheimer's Dis Other Dementiasr. 2013;28:216-22. https://doi.org/10.1177/ 1533317513481091.

106. Zwijsen SA, Niemeijer AR, Hertogh CM. Ethics of using assistive technology in the care for community-dwelling elderly people: an overview of the literature. Aging Ment Health. 2011;15:419-27. https://doi.org/10.1080/ 13607863.2010.543662.

107. Powell J, Chiu T, Eysenbach G. A systematic review of networked technologies supporting carers of people with dementia. J Telemed Telecare. 2008;14:154-6. https://doi.org/10.1258/jtt.2008.003018.

108. Bemelmans R, Gelderblom GJ, Jonker P, de Witte L. Socially assistive robots in elderly care: a systematic review into effects and effectiveness. J Am Med Dir Assoc. 2012;13:114-120.e1. https://doi.org/10.1016/J.JAMDA.2010.10.002.

109. Czarnuch S, Mihailidis A. Development and evaluation of a hand tracker using depth images captured from an overhead perspective. Disabil Rehabil Assist Technol. 2015:1-8. https://doi.org/10.3109/17483107.2015.1027304.

110. Agree EM, Freedman VA, Cornman JC, Wolf DA, Marcotte JE. Reconsidering substitution in long-term care: when does assistive technology take the place of personal care? J Gerontol Ser B Psychol Sci Soc Sci. 2005;60:S27280. https://doi.org/10.1093/geronb/60.5.S272

111. Miskelly F. Electronic tracking of patients with dementia and wandering using mobile phone technology. Age Ageing. 2005;34:497-9. https://doi. org/10.1093/ageing/afi145.

112. Topo P. Technology studies to meet the needs of people with dementia and their caregivers: a literature review. Academy of Finland and STAKES, P. O. Box 220, FIN-00531, Helsinki, Finland; e-mail: paivi.topo@stakes.fi: Sage Publications Inc.; 2008. doi:https://doi.org/10.1177/0733464808324019.

113. Bjørneby S, Topo P, Cahill S, Begley E, Jones K, Hagen I, et al. Ethical considerations in the ENABLE project. Dementia. 2004;3:297-312 https:// journals.sagepub.com/doi/10.1177/1471301204045162.

114. Armstrong N. Design, development and evaluation of assistive technologies to assist people with Alzheimers disease by supporting their caregivers: University of Ulster (United Kingdom); 2012. https://ethos.bl.uk/OrderDetails. do?uin=uk.bl.ethos.602343.

115. Bhattacharya S, Wainwright D, Whalley J. Internet of things (IoT) enabled assistive care services: designing for value and trust. Procedia Comput Sci. 2017;113:659-64. https://doi.org/10.1016/J.PROCS.2017.08.333.

116. Demir E, Köseoğlu E, Sokullu R, Şeker B. Smart home assistant for ambient assisted living of elderly people with dementia. Procedia Comput Sci. 2017; 113:609-14. https://doi.org/10.1016/J.PROCS.2017.08.302.

117. Greenhalgh T, Procter R, Wherton J, Sugarhood P, Hinder S, Rouncefield M. What is quality in assisted living technology? The ARCHIE framework for effective telehealth and telecare services. BMC Med. 2015;13:91. https://doi. org/10.1186/s12916-015-0279-6.

118. McShane R, Gedling K, Keene J, Fairburn C, Jacoby R, Hope T. Getting lost in dementia: a longitudinal study of a behavioral symptom. Int Psychogeriatrics. 1998;10:253-60 http://www.ncbi.nlm.nih.gov/pubmed/ 9785146. Accessed 10 Dec 2018.

119. Greenhalgh T, Wherton J, Sugarhood P, Hinder S, Procter R, Stones R. What matters to older people with assisted living needs? A phenomenological analysis of the use and non-use of telehealth and telecare. Soc Sci Med. 2013;93:86-94. https://doi.org/10.1016/J.SOCSCIMED.2013.05.036.

120. Gibson G, Dickinson C, Brittain K, Robinson L. Personalisation, customisation and bricolage: how people with dementia and their families make assistive technology work for them. Ageing Soc. 2018:1-18. https://doi.org/10.1017/ S0144686X18000661.

121. Holthe T, Wulff-Jacobsen I. Matching user needs to technology in dementia care: experiences with the Alma supervisor educational program. Fam Med Prim Care Rev. 2016:4:492-6. https://doi.org/10.5114/fmpcr.2016.63710.
122. McCabe M, You E, Tatangelo G. Hearing their voice: a systematic review of dementia family caregivers' needs. Gerontologist. 2016;56:e70-88. https:// doi.org/10.1093/geront/gnw078.

123. Scherer MJ, Craddock G, Mackeogh T. The relationship of personal factors and subjective well-being to the use of assistive technology devices. Disabil Rehabil. 2011;33:811-7. https://doi.org/10.3109/09638288.2010.511418.

\section{Publisher's Note}

Springer Nature remains neutral with regard to jurisdictional claims in published maps and institutional affiliations.

\section{Ready to submit your research? Choose BMC and benefit from:}

- fast, convenient online submission

- thorough peer review by experienced researchers in your field

- rapid publication on acceptance

- support for research data, including large and complex data types

- gold Open Access which fosters wider collaboration and increased citations

- maximum visibility for your research: over $100 \mathrm{M}$ website views per year

At BMC, research is always in progress.

Learn more biomedcentral.com/submissions 